\title{
La disputa por la universidad pública: antípodas en tiempos de la «cuarta transformación»
}

\section{Humberto Márquez Covarrubias*}

Resumen. Sobre la relación entre educación y desarrollo, la hipótesis convencional postula que para cambiar la economía hay que cambiar antes la educación, y la hipótesis crítica supone que para cambiar la educación antes hay que cambiar la economía, sin embargo los procesos de cambio social sustantivo precisan cambiar las dos esferas simultáneamente. Ante la tentativa, aún incierta, de un cambio de régimen político derivado de un gobierno que proclama una etapa de transformación de la vida nacional, la universidad pública debería jugar un papel fundamental en la generación de conocimiento, la enseñanza, la formación de fuerzas laborales especializadas y la producción de cultura. Para ello se requiere una gran transformación de la universidad pública. Se antepone una disyuntiva: o la reforma universitaria la impone el Estado, como sucede con la reforma neoliberal en curso, o la construyen las comunidades universitarias. La disputa por la universidad pública abre un debate amplio acerca distintos temas: deuda social del Estado y derecho social, heteronomía y autonomía, austeridad y sustentabilidad financiera, privatización y bien público, mercantilización y gratuidad, selectividad y obligatoriedad, diferenciación y equidad institucional, flexibilización y precarización y revalorización del trabajo académico, calidad y criticidad, empresarialidad y compromiso social, empleabilidad y formación de ciudadanía crítica, pedagogía digital y pedagogía crítica, evaluación punitiva y evaluación institucional, poder estructurado y democratización, gestión de la crisis y transformación universitaria, defensa y transformación.

Palabras claves: universidad pública, autonomía, gratuidad, obligatoriedad, México.

* Docente investigador de la Unidad Académica en Estudios del Desarrollo de la Universidad Autónoma de Zacatecas (UAZ), México. 


\section{Debates on the Public University: Antipodes in the era of the "Fourth Transformation»}

Abstract. With the anticipation of a political regime change resulting from an elected government that discursively gambles on a period of transformation in national affairs, the public university should play a fundamental role, given that it is a fountain of knowledge, a place for teaching, trainer of specialized labor forces and a producer of culture. In regard to the relationship between education and development, the conventional theory follows that in order to change the economy, one must first change education, or rather, one might assume the opposite - that in order to change education one must first change the economy-but the processes of social change require change in the two areas simultaneously. However, there is a dichotomy in that the university reforms are imposed from outside of their autonomy, by the State in fact, as has been seen in the neoliberal reform, or they are constructed from within the university communities. Currently, a debate continues behind the scenes regarding the public university, whose distinguishing features are debated between: the social debt of the State and its social obligation, heteronomy and autonomy, austerity and financial sustainability, privatization and public goods, commercialization and free access, selectivity and compulsory education, differentiation and institutional equity, flexibilization and precarity and the revaluing of academic work, quality and criticality, entrepreneurship and social pact, employability and the training of critical citizens, digital pedagogy and critical pedagogy, punitive evaluation and institutional evaluation, structual power and democratization, crisis management and university transformation, defense and transformation.

Keywords: public university, autonomy, free education, compulsory education, Mexico. 
Entre lo viejo que no termina de morir y lo nuevo que no termina de nacer.

Gramsci

¡Todo es igual, nada es mejor...?

Discépolo

\section{Transformación cuarta}

En el imaginario político del actual gobierno encabezado por Andrés Manuel López Obrador, México atraviesa por una supuesta cuarta transformación, que da continuidad a tres grandes hitos de la historia patria: la Independencia, la Reforma y la Revolución. Independientemente de que resulta prematuro nombrar y darle un rango histórico con tales parangones al gobierno que está en su primer año de funciones, cabe advertir que el referente más inmediato se remonta no a dos siglos atrás —o cinco, para quienes insisten en la conquista—, sino, más modestamente, a las últimas tres décadas y media.

La gran transformación que ha experimentado recientemente México es la imposición del proyecto neoliberal dentro de la trama de un capitalismo subdesarrollado y dependiente que persiste como sustrato histórico y estructural que ha modulado distintas configuraciones políticas. En ese marco, se advierten cuatro movimientos: a) cambio del modelo de desarrollo: el proyecto desarrollista alimentado por la industrialización por sustitución de importaciones y el llamado desarrollo estabilizado, centrado en la gestión estatal y la renta petrolera es derrocado para implantar el proyecto neoliberal, para entronizar al gran capital transnacional, la 
desnacionalización y privatización y la orientación hacia el flujo exportado; b) cambio en la relación Estado-universidad pública: el proyecto de universidad popular o de masas que había sido impulsado por el modelo desarrollista es reconvertido hacia una universidad neoliberalizada bajo las pautas del mercado, la austeridad presupuestal, la mercantilización y la privatización; c) cambio dentro de la universidad: la neoliberalización de la universidad pública significa una contrarreforma, que va de la autonomía, gratuidad y compromiso social a la heteronomía, mercantilización y empresarialidad, y $d$ ) cuarto movimiento: con el triunfo electoral del frente electoral denominado «cuarta transformación», se abre la expectativa de cambiar el modelo neoliberal y, con ello, eventualmente, imprimir un nuevo ciclo de reforma universitaria en sentido progresista y orientado a la transformación social. El tránsito del neoliberalismo al posneoliberalismo es un proceso en ciernes, ambiguo y contradictorio, que expresa la disputa de intereses encontrados por un nuevo proyecto de nación.

\section{Deuda social del Estado o derecho social}

La deuda social se refiere al saldo negativo que ha dejado el Estado neoliberal en las clases sociales populares al implementar medidas de austeridad (en realidad de ajuste) para recortar la política de redistribución del ingreso y con suprimir o mercantilizar los bienes y servicios públicos plasmados en programas sociales: educación, salud, vivienda, alimentación, transporte, ciencia, cultura, esparcimiento. Generalmente se expropian fondos públicos para el desarrollo social y se orientan a favor del capital financiero, transferencias al sector privado, gastos burocráticos y militarización. En el 
rubro de la universidad pública, se traduce en una baja cobertura educativa, signo de la exclusión social.

El Estado se financia con impuestos, deuda o ingresos de empresas públicas, es decir, se apropia de una fracción importante del valor generado por el trabajo colectivo, pasado, presente y futuro, y según su discrecionalidad e intereses, lo redistribuye entre las distintas clases y sectores sociales. La cuestión fiscal, presupuestal y los bienes públicos, donde está inmersa la educación pública, son una temática crucial, en disputa.

Pero los derechos sociales no son concesiones del Estado sino conquistas sociales alcanzadas en ciclos de lucha transgeneracionales a cargo del movimiento obrero y el movimiento popular en general. Son derechos que siempre tienen que ser defendidos, pues permanentemente son atacados. En esa trama, el neoliberalismo significó una colosal embestida en contra de los derechos laborales y sociales, y la expectativa de un proyecto social posneoliberal no es garantía del resarcimiento de los derechos, es apenas el anuncio de un nuevo ciclo de luchas reivindicativas. Una política socialmente progresista requiere una política de Estado, pero también de un poder social actuante, una nueva correlación de fuerzas, no subordinada al gobierno en turno, sino independiente, capaz de imponer sus intereses y necesidades a las instituciones, que tienden a ser conservadoras y restrictivas.

En la autodenominada «cuarta transformación», que encabeza el presidente Andrés Manuel López Obrador luego del triunfo electoral en 2018, que plantea un discurso antineoliberal, aunque en la práctica política del primer año de gobierno continúa y profundiza el llamado modelo neoliberal, no se advierte un proyecto educativo nacional que incluya una reestructuración institucional, la articulación de todos los niveles educativos y 
la orientación de la investigación para promover un proyecto de transformación social, tampoco se promueve una reforma educativa con nuevos contenidos, filosofía, orientación y pedagogía asociados a un cambio de régimen político y económico. Simplemente, se plantea la derogación de la reforma educativa del gobierno anterior, referente a la educación básica, para abrir cauce a la llamada «nueva escuela mexicana», con énfasis en la educación primaria. Sin embargo, se trata de una reforma más, de carácter parcial, sobre la reforma educativa precedente, la cual había sido cuestionada por estar orquestada por organismos empresariales y, sobre todo, por carecer de contenido educativo y, en lugar de ello, centrarse en el ámbito laboral y la implementación de mecanismos de evaluación punitivos, es decir, asociados al despido.

La propuesta educativa de la cuarta transformación es difusa, no dispone de un proyecto claro, conciso y articulado para impulsar una genuina transformación social. Se pueden entrever algunos elementos: la reforma del artículo $3^{\circ}$ constitucional, la ley general de educación, el proyecto de la «nueva escuela mexicana», el programa de becas y el sistema de Universidades para el Bienestar Benito Juárez García (UBBJ). No obstante, la propuesta educativa de la cuarta transformación se basa en un modelo de gestión, pero no en un proyecto educativo para la transformación social. Más que un proyecto educativo que sustente la transformación social en una nación subsumida en el subdesarrollo y la dependencia, la proposición del gobierno morenista representa, tal como lo fuera el proyecto anterior, un modelo de gestión del sector educativo, por sectores y sin vínculos con un posible proyecto de transformación social. Gira en torno a la idea de abrogar la reforma anterior para suprimir el carácter laboral punitivo, de conformidad a un pacto electoral entre Andrés Manuel López Obrador y 
las dos expresiones confrontadas del magisterio, el Sindicato Nacional de Trabajadores de la Educación (SNTE) y la Coordinadora Nacional de Trabajadores de la Educación (CNTE), la primera de las cuales fuera impulsora de la reforma anterior. Aunque sigue teniendo un sesgo laboral, es decir, se trata de un régimen de excepción para el magisterio, ajeno al artículo 123, referente al trabajo. La propia CNTE se ha mostrado muy escéptica de la supuesta abrogación de la reforma educativa y ha señalado, por ejemplo, que la sustitución del concepto de evaluación por la revaloración del maestro a través de la educación continua en el fondo mantiene muchos de los postulados de la reforma precedente.

Existe menos claridad para el nivel de educación superior. Como premisa discursiva, se critica a los exámenes de selección como mecanismo de exclusión de jóvenes de escasos recursos y la consecuente falta de posibilidades de ingreso de miles de jóvenes a las instituciones de educación superior (IES), que abarca al conjunto de universidades públicas autónomas federales y estatales, universidad pedagógica, universidades politécnicas y tecnológicas, universidades interculturales, escuelas normales. Ante dicha circunstancia, como también lo dijera el gobierno de Enrique Peña Nieto, se propone la ampliación de la cobertura, pero ahora con otros mecanismos, no a partir de las IES existentes, que incluye a las instituciones públicas y privadas, o de la ampliación presupuestal a las universidades públicas asociado a un programa de regeneración institucional y de recomposición del entramado estatal compuesto por la Secretaría de Hacienda y Crédito Público (SHCP) y la Secretaría de Educación Pública (SEP). Si no que con la intención de hacer efectivas las oportunidades de educación para todos, la propuesta concreta es el programa de UBBJ, creada por decreto el 30 de julio de 2019, que consiste en la apertura de 100 nuevas universidades. En 
realidad, más que de 100 universidades, se trata de una sola universidad con planteles dispersos en 80 municipios que abarca en conjunto 36 carreras en seis áreas del conocimiento, pero en realidad no son universidades, pues no realizan trabajos de investigación, no conjugan una variedad de carreras de las ciencias sociales y las humanidades y las ciencias naturales, sino son una especie de escuelas profesionales o centros de capacitación para el trabajo con un programa único de corta duración por cada plantel con objeto de profesionalizar a jóvenes con pocas posibilidades de acceso o movilidad hacia los campus universitarios urbanos. En el primer año de gobierno sólo se han abierto 87 de 100 centros. El comienzo ha sido azaroso, pues la misma Secretaría de Hacienda y la Secretaría de Educación Pública no le han otorgado recursos y operan en condiciones deplorables, los profesores no reciben su salario y los estudiantes cooperan para adquirir útiles y se organizan para realizar labores de limpieza. Que tendría la meta de atender el primer año a 15 mil alumnos. Sin embargo, la realidad es que el sistema UBBJ ha comenzado con exiguos recursos presupuestales y con la persistencia de la crisis de las universidades públicas autónomas, sobre todo las estatales.

Los problemas de fondo de la educación superior, como la profunda crisis de la universidad pública autónoma y la desarticulación del conjunto del sistema educativo mexicano, han sido dejados al garete en la etapa inicial de la cuarta transformación, pese a que la educación pública es un derecho social básico y es eslabón crucial para cualquier proceso de transformación social. Peor aún, en lugar de elaborar un diagnóstico profundo, realista, de la universidad pública, y de formular un proyecto educativo sexenal, simplemente se difunde un discurso que cuestiona a las universidades y a los académicos. Por ejemplo, López Obrador critica a los profesores 
de la Universidad Autónoma de Morelos (UAM), a quienes les dice que les daría dinero público para su institución, pero tendrían que dejar atrás sus corruptelas y privilegios. El discurso de la corrupción y el privilegio ha sido un artilugio recurrente de los organismos financieros internacionales y de la derecha empresarial para atacar a las instituciones públicas y a los sindicatos, sobre todo a los derechos sociales y bienes públicos, y ha sido recogido por los políticos de nueva izquierda que se adhieren a las consignas neoliberales. López Obrador suele recurrir a este discurso para atacar a los adversarios políticos de las administraciones anteriores, pero también lo esgrime como argumento justificatorio para desmontar programas, empleos, servicios y bienes del sector público, así como para recortar drásticamente presupuestos en esferas como el campo, los municipios, la salud y la educación.

\section{Heteronomía o autonomía}

La autonomía universitaria representa una invaluable conquista histórica alcanzada por los universitarios producto de luchas de estudiantes y profesores en distintos momentos de la vida nacional, que se remonta al «grito de Córdoba» en 1918, el hito histórico de la reforma universitaria, que se propagó por el resto de América Latina, y se ha consolidado como un fundamento institucional que posibilita un ámbito de libertad académica para el cumplimiento de la misión educativa que ha sido conferida a las universidades públicas, merced a las luchas universitarias (Sader, Aboites y Gentili, 2008).

Desde la perspectiva del Estado, en términos generales la autonomía significa la transferencia de funciones de servicio público propias del Estado 
a otras entidades. ${ }^{1}$ Sin embargo, la autonomía universitaria es específica de las instituciones educativas de educación superior y difiere de la autonomía otorgada a organismos o instancias de la administración pública y de las entidades, que realizan funciones gubernamentales delegadas, bajo la pauta de la gobernanza neoliberal, como el Banco de México (Banxico), el Instituto Nacional Electoral (INE), el Instituto Nacional de Estadística Geografía e Informática (INEGI), la Comisión Nacional de Derechos Humanos (CNDH), entre otros, ${ }^{2}$ y también es diferente de la autonomía de las comunidades, como los pueblos originarios, que se rigen por usos y costumbres, pero que están inmersos en el Estado nación y sus leyes. En el caso de la educación superior, se otorga la autonomía a las universidades públicas y se le confiere la misión educativa respectiva. La autonomía está reconocida en el marco jurídico, pero no es una pura concesión estatal sino que es fruto de luchas sociales que la han reclamado, conquistado y ejercido. ${ }^{3}$ Básicamente se refiere a la facultad

${ }^{1}$ El Estado otorga la autonomía a organismos descentralizados, por lo que no es concebible que las dependencias u organismos que están incrustados en la estructura gubernamental puedan ser autónomos, pero algunos organismos descentralizados pueden no ser autónomos, aunque los organismos autónomos son necesariamente descentralizados. Mediante la descentralización, la autoridad central se desprende de algunas funciones y decisión para trasladarlas a esas instancias que asumen una competencia específica.

${ }^{2}$ Aparentemente, la autonomía es una concesión jurídica a favor de instituciones públicas para que cumplan funciones públicas, pero bajo el influjo de la gobernanza neoliberal, cada vez más existen organismos públicos autónomos que responden a intereses privados y cumplen el papel de socavar la función pública según las exigencias del capital privado, que arguye un juego de «pesos y contrapesos» bajo el velo de la legalidad, la transparencia y la rendición de cuentas.

${ }^{3}$ Pero pareciera no siempre estar suficientemente claro, por ejemplo, la Segunda Sala de la Suprema Corte de Justicia de la Nación emitió una sentencia unánimemente sobre el fallo dictado por un juez de distrito que amparaba y protegía a la Universidad Autónoma del Estado de Hidalgo (UAEH) contra los actos del Gobierno y el Congreso de esa entidad, y ante la solicitud de revisión determinó que: «La autonomía de las universidades tiene un estatus especial que no debe asimilarse a otros órganos o entidades autónomos creados por la 
de la comunidad universitaria para dotarse de sus propias normas, formas de gobierno, y la faculta de diseñar planes de estudio, programas educativos, proyectos de investigación, además de ejercer la libertad de cátedra. Con la autonomía, las universidades públicas pueden determinar sus políticas de ingresos, mecanismos de evaluación, planes de estudios e integración de carreras.

La autonomía universitaria suele ser atacada desde distintos frentes, externos e internos: los organismos internacionales que proclaman la privatización y mercantilización de la educación superior, los organismos públicos y privados que evalúan el desempeño de las universidades y de los universitarios e imponen parámetros para acceder a recursos financieros, el Estado y sus instancias de gobierno que implementan políticas de austeridad e imponen agendas de contrarreforma, los grupos empresariales y políticos, los medios de comunicación. Desde los círculos políticos proclives al neoliberalismo se ataca la autonomía de las universidades públicas, pero en cambio se exige el respeto a los órganos autónomos, en referencia a las modalidades que han proliferado bajo la gobernanza neoliberal para debilitar al Estado, motivar la división de poderes y abrir espacios de injerencia al sector privado en ámbitos administrativos para ejercer funciones relevantes de gobierno, pero que están en una misma sintonía de resguardar los lineamientos financieros internacionales y otras materias correlativas, más allá del Estado nacional.

Desde adentro, la autonomía también es vulnerada cuando no se recurre a la comunidad universitaria para resolver, en primera instancia, los problemas que atañen a la propia universidad y en lugar de ello se acude a

Constitución Política del país, o las entidades federativas». Dicha resolución es de carácter definitivo y tiene trascendencia nacional, por lo que será referente en causas parecidas a nivel local y nacional. 
las instancias externas y a los acuerdos alcanzados en esos ámbitos que luego se imponen a la comunidad universitaria. Entonces se debilita la esencia misma de la universidad, que indiscutiblemente es la autonomía. De ahí que un principio básico de la conducción de la vida universitaria, pese a su heterogeneidad y diferencias, sea fortalecer la relación entre los miembros de la comunidad universitaria: directivos (rectoría, administración, directores), académicos (profesores, investigadores), estudiantes y trabajadores administrativos y manuales. No para imponer criterios burocráticos, intereses de grupos políticos o preservar espacios de poder, sino para replantear el papel de la universidad en la sociedad, a la cual se debe, procurando observar, en todo momento y lugar, la legalidad, la transparencia y la democracia.

De manera inopinada, el gobierno de Andrés Manuel López Obrador, que se supone habría de transformar la vida nacional desde una perspectiva favorable a los sectores populares, formuló una iniciativa de reforma al artículo $3^{\circ}$ constitucional que excluyó la fracción VII, que a la letra dice:

Las universidades y las demás instituciones de educación superior a las que la ley otorgue autonomía, tendrán la facultad y la responsabilidad de gobernarse a sí mismas; realizarán sus fines de educar, investigar y difundir la cultura de acuerdo con los principios de este artículo, respetando la libertad de cátedra e investigación y de libre examen y discusión de las ideas; determinarán sus planes y programas; fijarán los términos de ingreso, promoción y permanencia de su personal académico; y administrarán su patrimonio. Las relaciones laborales, tanto del personal académico como del administrativo, se normarán por el Apartado A del Artículo 123 de esta Constitución, en los términos y con las modalidades que establezca la Ley Federal del Trabajo conforme a las características propias de un trabajo especial, de manera que concuerden 


\section{LA DISPUTA POR LA UNIVERSIDAD PÚBLICA}

con la autonomía, la libertad de cátedra e investigación y con los fines de las instituciones a que esta fracción se refiere (Orden Jurídico Nacional, s/f).

En cambio, la iniciativa firmada por López Obrador modificaba el artículo para simplemente dejar por escrito que «la impartición se realizará con apego a los fines que establecen en el párrafo primero y la fracción II de este artículo para alcanzar el bienestar de la población, así como cumplir los planes y programas a que se refiere la fracción V del mismo».

Este episodio generó críticas de los universitarios y Esteban Moctezuma, secretario de Educación Pública, quien procede del sector empresarial y enarbola la ideología de la derecha, tuvo que recular arguyendo que se trataba de un «error» en la captura mecanográfica, puesto que en lugar de señalar la fracción «VII» debió haber dicho «a) de la fracción VII», por lo que esta errata sería enmendada. Con esa corrección, la referencia a la autonomía universitaria volvía a figurar en el texto. No obstante, este hecho, más que un error de captura, pareciera expresar el juego de intereses políticos que afloraron en este altercado que no fue aclarado en su momento con suficiencia y en cambio quedó expuesta la forma lamentable en que se improvisan las reformas de gran calado sin medir consecuencias sociales. ${ }^{4}$

Pero más allá de la controversia letrista sobre la vigencia de la autonomía universitaria y su necesaria defensa y preservación en el texto constitucional, es imprescindible hacer un alto en el camino y reflexionar

\footnotetext{
${ }^{4} \mathrm{Al}$ respecto, el presidente López Obrador tuvo que recular y aseguró que las universidades mantendrán su autonomía: «No hay ninguna intención (de eliminar la autonomía). Si es necesario, estamos dispuestos a que se agregue lo de la autonomía, para salirle al paso, porque si no están esperando que nos equivoquemos o que se cometa cualquier error y hay que enmendarlo pronto, porque si no se va a convertir en tema de los que están a disgusto por la decisión que tomamos, van a querer agarrar eso de bandera, por eso es mejor aclararlo», aseguró en Palacio Nacional.
} 
concienzudamente sobre las múltiples formas en que la autonomía universitaria ha venido siendo atacada sin necesidad de modificar el artículo de referencia. La política neoliberal ha tomado como presa a las universidades públicas autónomas para imponer medidas que generan un ambiente contrario de heteronomía a través de la política de austeridad y financiamiento condicionado, las evaluaciones externas y la acreditación acorde a criterios de mercado; además de la generación de un ambiente de incertidumbre que posibilita las negociaciones políticas con las autoridades educativas y hacendarias, la intervención de los gobernadores y la intrusión de los partidos; sin olvidar el mayor influjo del capital privado mediante el financiamiento de empresas y fundaciones, entre otras medidas.

Cabe advertir que, pese al entusiasmo o compromiso que asumen algunas universidades o sus dirigentes con el proyecto de la cuarta transformación, y por muy loables que puedan parecer algunos de sus objetivos, no debe ligarse a la universidad pública con las políticas de los gobiernos en turno. Preservar el ámbito de la autonomía es un aspecto crucial para garantizar la libertad de pensamiento, de cátedra y de investigación, y un fundamento irrenunciable para generar espacios de debate crítico sobre el Estado, los gobiernos y sus políticas.

Más allá de la carta constitucional, hacer realidad la restitución de la autonomía en la práctica es un factor determinante para responder efectivamente a la crisis de la educación superior en general y para reconstruir a las universidades públicas en particular. Es insuficiente recuperar el texto de la fracción VII borrado inicialmente en el proyecto presidencial, además se tienen que crear las bases institucionales (normativas y presupuestales) para que el principio de la autonomía sea un soporte efectivo, en todos sus términos, para el conjunto de las universidades públicas del país. 


\section{Austeridad o sustentabilidad financiera}

Históricamente, el desarrollo del capitalismo no sigue un orden progresivo ascendente sino que se despliega afrontando contradicciones crecientes y crisis recurrentes. La tendencia inexorable a la caída de la ganancia es contrarrestada de manera limitada y provisional de diversas maneras, como la exigencia de incrementar el grado de explotación de los trabajadores. En esa lógica, se han impuesto los programas de ajuste estructural de corte neoliberal que tienen el cometido básico de desvalorizar la fuerza de trabajo, por vías directas (la precarización del trabajo) e indirectas (como el TLCAN, ahora T-MEC). En esa lógica indirecta se inscribe el desmantelamiento de los servicios públicos, vía la privatización o la austeridad, que los liquida de manera fulminante o paulatina.

La austeridad es un programa económico de shock que ha sido enarbolado por los organismos financieros internacionales, el capital financiero y las derechas cuyo cometido es desmantelar los servicios públicos y la capacidad del Estado para garantizar derechos sociales, significa recortes al gasto social del Estado, el dogma del superávit primario, la política fiscal regresiva, los subejercicios, el despido de trabajadores, el cierre de programas sociales, y en contrapartida, la transferencia de recursos públicos al capital financiero, la canalización de recursos al sector privado, el aumento del gasto en militarización. Bajo esta rúbrica, se constriñen los apoyos a la educación, salud, alimentación, vivienda, transporte y cultura. Por lo que ataca los derechos sociales y la reproducción social de las clases populares, y se abre el camino para el control social clientelar, por sectores privados o gobiernos populistas.

En el ámbito educativo, los neoliberales argumentan que no existe una correlación positiva entre el gasto público en educación y los retornos en la 
inversión educativa, que no existe un saldo positivo entre egresados y niveles de ingreso y empleo de los universitarios y que la formación universitaria no repercute en mejoras de la competitividad, es decir, la problemática se constriñe a cuestionar la eficiencia en el gasto educativo, que se refleja en bajos niveles de retorno, empleabilidad y competitividad. No sólo se cuestiona el papel de las universidades a partir de indicadores de mercado sino que se llega al extremo de plantear la idea del fin de las universidades.

Por supuesto que la crisis de la universidad pública autónoma no es sólo financiera, sino que es multidimensional, pero es indudable que el estrangulamiento presupuestal maquinado por la tecnocracia neoliberal ha fungido como Caballo de Troya que dentro de las universidades socaba la autonomía, el carácter público, la gratuidad y las funciones educativas e investigativas. No puede plantearse un desarrollo institucional y adquirir compromisos sociales sin tener un soporte material y, en tal sentido financiero, que lo respalde.

La gestión neoliberal se ha destacado por imponer una política de desfinanciamiento a las universidades públicas que ha impedido la creación de nuevas universidades, la contratación de personal suficiente, el financiamiento a investigación científica y fomento cultural. ${ }^{5}$ En lugar de desarrollo institucional se registra la inducción de las crisis financieras recurrentes y deterioro institucional y la gestión de la crisis como mecanismo

${ }^{5}$ En 1992, el entonces secretario de Educación Pública, Ernesto Zedillo, quien sería luego presidente de la República, criticó abiertamente al modelo de educación pública superior, al considerarlo «agotado e inviable», y en el contexto de las negociaciones del Tratado de Libre Comercio de América del Norte (TLCAN), anunció un nuevo esquema de financiamiento basado en la sujeción a los estándares de «excelencia y pertinencia», acorde a las proclamas del Banco Mundial y la OCDE como requisito para autorizar subsidios adicionales y la advertencia de que el gobierno asume la potestad de «influir», vía la asignación presupuestal, en las universidades (Aguirre y Pastrana, 1999). Desde entonces persiste esa norma de financiamiento condicionado y restricción presupuestal. 
de regulación y control y de implementación del programa de contrarreforma neoliberal.

El crecimiento relativo de la matrícula (aún insuficiente si se considera la baja cobertura) contrasta con el decrecimiento inducido en el presupuesto educativo, acorde a la norma de la austeridad neoliberal. A partir de 2000, la matrícula universitaria se ha incrementado 122 por ciento, pero al mismo tiempo el subsidio por alumno ha disminuido en -21.3 por ciento (ANUIES). El déficit presupuestal de las universidades mexicanas se ha profundizado bajo el influjo del neoliberalismo. Esta situación es más aguda en las universidades públicas autónomas de los estados. En el contexto de la Organización para la Cooperación y el Desarrollo Económicos (OCDE), México es el país con menor gasto acumulado por estudiante. De manera similar ocurre con la inversión destinada a ciencia, tecnología e innovación, que equivale a menos de 0.5 por ciento del Producto Interno Bruto (PIB), una diferencia importante respecto del promedio de la OCDE de 2.4 por ciento.

En contravención a reforzar el carácter público, autónomo y gratuito de la educación pública superior, en su primer ejercicio presupuestal, el presidente López Obrador, fiel al precepto neoliberal de la austeridad, envió un proyecto de presupuesto que contemplaba una reducción de 35 por ciento del monto asignado a la educación superior con respecto al año anterior ( «la reducción a educación superior asciende a mil 713.8 millones de pesos menos respecto del año pasado, monto que representa una caída de 6.2 por ciento en términos reales») (Román, 17 de diciembre de 2018), en contraste, se incrementa el presupuesto al sector militar, donde la Secretaría de la Defensa Nacional (Sedena) incrementará 10 por ciento. ${ }^{6}$ Esto es una muestra

${ }^{6}$ La política de austeridad recorta presupuestos en casi todas las áreas de la administración pública. Mientras que algunos rubros han sido sometidos a reducciones de hasta 70 por ciento, 
palpable de las prioridades políticas de un gobierno de «izquierda» y del sentido que pretende dársele a la denominada «cuarta transformación».

Más aún, López Obrador ataca a las universidades públicas, confundiendo los ámbitos de autonomía, recurriendo al discurso monocromático y machacón de que en ellas persiste la «corrupción» y los «privilegios», y no duda en reproducir el mantra neoliberal como solución al estrangulamiento financiero, pues dice que se tiene que «hacer más con menos» (Rodríguez, 17 de diciembre de 2018), enunciados que son propios de la derecha empresarial para carcomer los bienes públicos, los derechos sociales y los derechos sindicales, no corresponde a un proyecto de izquierda. Si bien hay testimonios de corrupción, esto tiene como origen el estrangulamiento presupuestal y la obligación de buscar vías alternas de financiamiento, que embona con la corrupción institucional del Estado que a través de las secretarías de Estado funge como el agente corruptor y toma como presas o cómplices a determinados funcionarios de universidades, a quienes logra seducir y corromper, para triangular recursos, como se ha documentado en la llamada «estafa maestra». No obstante, esta práctica no se ha generalizado, y es insostenible inculpar a

hay algunos - muy pocos — que gozan de gran cantidad de recursos. Uno de ellos es el de la seguridad que, para el siguiente año, el gobierno que encabeza Andrés Manuel López Obrador destinará 197 mil 254 millones 910 mil pesos, la mayor parte dirigido al sector militar. Para 2019, «los recursos asignados a la educación superior en el proyecto de PEF 2019, proyecta una reducción respecto a 2018 de mil 713.8 millones de pesos a las instituciones federales, una caída de 6.2 por ciento en términos reales. En el caso de las universidades públicas estatales, institutos tecnológicos, universidades tecnológicas y politécnicas, aunque tienen un incremento de 471.2 millones de pesos, si consideramos la inflación, representa una reducción de 3.2 por ciento en términos reales. Los fondos extraordinarios concursables para el desarrollo profesional docente, la ampliación de la oferta educativa, y la mejora de la calidad, se reducirían en mil 843.5 millones de pesos, lo que equivale a una disminución en términos reales del 43.6 por ciento. De igual forma, los recursos destinados al Conacyt presentan una disminución de 2 mil 561.2 millones de pesos, equivalentes al 12.8 por ciento» (ANUIES, 17 de diciembre de 2018). http://www.anuies.mx/media/docs/avisos/pdf/1812171934462019.pdf 
las universidades públicas de ese latrocinio, con el propósito velado de presentarlas como corruptas y ahondar su desprestigio y justificar el declive en el financiamiento. En tal caso corresponderá a las instancias competentes, a la Auditoría Superior de la Federación o a la Fiscalía General de la República, fincar las responsabilidades correspondientes, pero más importante es señalar que se requiere altura de miras para eliminar el discurso que criminaliza a las universidades y a los universitarios que se presentan como instituciones y personajes colmados de un estigma de «privilegios» con el objeto de justificar los ajustes draconianos y la imposición de la austeridad neoliberal. Ello sin tomar en cuenta el discurso antiintelectual en contra de científicos y académicos a quienes se atribuyen privilegios (Muñoz y Urrutia, 29 de mayo de 2019), incluso se ha llegado al extremo de obligar a científicos a pedir permiso al presidente para viajar al extranjero a congresos, pues dice que se trata de «turismo académico» y otras expresiones despectivas. Por si fuera poco, el basamento discursivo de la cuarta transformación se aleja de la ciencia y el pensamiento crítico, para apoyarse en el pensamiento mágico, específicamente en el cristianismo evangélico y en proclamas moralistas apegadas a valores tradicionales y familiares que tienen el cometido de exaltar la figura mesiánica, antes que afirmar positivamente las instituciones educativas y científicas. ${ }^{7}$

Pero esos alegatos no eximen al Estado de su obligación para financiar a la educación superior y menos de recortar los presupuestos desde las anteojeras de la «austeridad republicana» o la «austeridad franciscana» que predica el presidente, y que es una forma discursiva de encubrir la política

${ }^{7}$ Cabe recordar que la fracción II del Artículo $3^{\circ}$ constitucional señala que la educación estará guiada bajo los «resultados del progreso científico, luchará contra la ignorancia y sus efectos, las servidumbres, los fanatismos y los prejuicios». 
neoliberal impuesta sobre la educación pública superior, desde sexenios anteriores y que perdura en el presente. La crítica soterrada a las instituciones públicas tachándolas como corruptas y la aplicación unilateral de programas de ajuste son políticas típicamente neoliberales que en nada abonan a un gobierno de la «cuarta transformación».

Ha sido la inconformidad y presión de los universitarios, además del recordatorio de que AMLO se había comprometido ante los rectores de la Asociación Nacional de Universidades e Instituciones de Educación Superior (ANUIES) a mantener el presupuesto del año pasado más la inflación, lo que modificó el presupuesto lopezobradorista, pero fue una victoria pírrica, pues apenas se logró igualar los montos del presupuesto del año previo. Por lo que se enmendó la plana, pero se dejó en la misma condición de precariedad a las universidades estatales con crisis financieras recurrentes, por acumulación de deudas e insolvencia. Es decir, al menos en este rubro, «todo cambia para que todo siga igual».

En esa tónica, varias universidades estatales fueron, de nueva cuenta, «rescatadas» con recursos extraordinarios, como se ha venido haciendo durante el periodo neoliberal, pero de manera condicionada a la firma de cartas de intención que las obligan a implementar programas de austeridad, en realidad de ajuste, que incluye despidos a personal, la no renovación de contratos y la no contratación de más personal. Evidentemente, esto no resuelve el problema estructural de las universidades.

Para evitar estas presiones se requiere una legislación sobre la universidad pública y que incluya criterios para el financiamiento de las universidades públicas con presupuestos anuales progresivos, además de revisar las deudas y encontrar caminos de solución, que pueden incluir la condonación de pasivos, y el saneamiento de las universidades. El Estado 
neoliberal ha rescatado a empresas y capitales privados, mientras que estranguló a instituciones públicas.

Sin embargo, nunca será suficiente plasmar en la carta constitucional ni pronunciar discursos elocuentes que enarbolen los prístinos principios de autonomía, gratuidad y obligatoriedad de la educación pública superior, si en efecto no existe voluntad política para y por tanto no se otorgan los recursos financieros suficientes en los presupuestos a efecto de que las universidades hagan valer la educación como un derecho social y un bien público y, que además, permitan el verdadero desarrollo institucional. No es legítimo enunciar proclamas antineoliberales sin crear las bases y los soportes materiales para que las universidades públicas abandonen en definitiva la exigencia que ha implantado el neoliberalismo de subsanar los vacíos presupuestales impuestos por la austeridad mediante el cobro de cuotas y la venta de diversos servicios educativos e investigativos.

De manera contundente, el Estado debe ser garante de la gratuidad y la obligatoriedad, por lo que además de actualizar y mejorar el artículo $3^{\circ}$ constitucional desde una perspectiva progresista, con el concurso de conocedores, investigadores y representantes legítimos de las universidades públicas, se deben crear los fondos públicos que de manera específica se fijen ese cometido. Estos fondos también necesitan ser plasmados en el cuerpo legislativo, sea en el artículo principal o en los transitorios, y en leyes secundarias o reglamentarias, para que se afiance una política de Estado y se establezcan las reglas claras y los procedimientos auditables. El proyecto legislativo puede incluir, sería deseable, una ley general de educación o una ley de educación superior, donde se plasme el carácter multianual y progresivo del presupuesto universitario. En caso de que sea inevitable cobrar cuotas hasta hacer posible que el Estado aporte por entero 
los recursos necesarios, se pueden fijar los montos de cuotas permisibles, con equivalencias, además de fijar los recursos que el Estado vaya ejerciendo paulatinamente hasta llegar a cumplimentar la meta de la gratuidad en la educación pública superior. Asimismo, la meta de obligatoriedad tiene que ser cubierta con fondos públicos que pueden ser calculados y programados de acuerdo con la expansión de las capacidades institucionales y con las necesidades sociales. ${ }^{8}$

Una política real de transformación de la universidad pública autónoma, en el marco de un verdadero proyecto de transformación social, reclama la instauración de un presupuesto suficiente y progresivo, que esté fijado en la ley. En este punto, cabe instaurar el principio de no regresividad presupuestaria en educación superior o, dicho en sentido positivo, la progresividad en el derecho humano a la educación.

La educación pública superior no puede continuar sujeta a las negociaciones políticas de ocasión y a los chantajes de los gobernantes y legisladores de turno, que quieren atribuirse en cada ciclo fiscal el salvamento de las universidades en crisis otorgando exiguos recursos extraordinarios que, apenas logran sobrellevar los apremios de coyuntura sin resolver los problemas estructurales de largo plazo, donde las universidades son cartas de negociación política.

Inobjetablemente, es imposible promover cambios educativos sustanciales y legislar derechos y obligaciones en una constitución progresista sin asignar los recursos suficientes. De ser así, la transformación quedará, una vez más, en demagogia. Razón por la cual se precisa de la conformación de

${ }^{8}$ Por ejemplo, según algunas estimaciones, de 7 a 10 mil millones de pesos cada año adicional, para llegar a 170 mil, lo queda en total 120 mil millones de pesos al año que tiene que sumarle el gobierno a lo que está dando a educación superior pública (Ordorika). 
un fondo destinado expresamente a cubrir los requerimientos materiales y presupuestales de la obligatoriedad y gratuidad en las universidades públicas autónomas.

\section{Privatización o bien público}

La universidad pública ha sido atacada con denuedo, desde el propio Estado y decididamente desde el sector privado, para desvanecer paulatinamente su carácter público, en tanto derecho social y bien público, mediante la privatización y la mercantilización de la educación superior y la consecuente configuración de un mercado de servicios educativos. No sólo han crecido desmesuradamente las instituciones privadas que toman una parte importante de la educación superior y la convierten en un mercado lucrativo, que van desde las universidades y tecnológicos de élite hasta las universidades «patito», sino que dentro de las propias universidades públicas avanzan formas soterradas de privatización como el financiamiento de intereses corporativos privados a proyectos de investigación, programas educativos y becas, la implementación de evaluaciones por instancias externas privadas internacionales y nacionales, que incluyen los rankings como mecanismos de clasificación de mercado y la indexación de publicaciones académicas, la adopción de formas de gestión gerenciales basados en la competitividad, la reconversión de proyectos educativos acordes a los requerimientos empresariales y patronales, entre otros mecanismos.

En el contexto del capitalismo neoliberal, bajo el precepto de la austeridad, los ataques frontales a los servicios públicos, como la educación pública superior, pero también de la salud, la alimentación, están a la orden 
del día. Es significativo el hecho porque los servicios públicos son componentes indirectos del salario directo, el cual también está siendo socavado. Por lo cual, la defensa tanto del salario como de los servicios públicos, que incluye la educación, resulta una lucha social imprescindible para superar la imposición del ajuste estructural neoliberal. Respecto a la educación, esto supone rechazar la gestión de los servicios públicos privatizados o subrogados, pero también los servicios públicos mal planteados y sin sustento, porque terminan por conculcar los derechos. No sólo es un rechazo teórico o argumental, sino también una lucha de los universitarios y de las clases populares en pos de preservar la propiedad y la gestión públicas de los servicios educativos, en conjunción con otros derechos sociales y laborales. La defensa de los derechos, que son conquistas de los trabajadores, tiene que ser incondicional, sin ambigüedades. No se puede someter a ninguna condición, ni sujetarse a programas de austeridad, de ahorro forzoso, de subejercicio presupuestal, de déficit presupuestal, de pago de deuda, ni de otras medidas regresivas, puesto que nada puede tener más peso social que los derechos.

Aun dentro de la trama del capitalismo, cabe la posibilidad de impulsar las causas sociales y hacer posible que se cristalicen, así sea relativamente, al sacarlas de la órbita del mercado, para fijarlas como derechos que sean garantizados mediante la cobertura estatal. De ahí la necesidad de defender y ampliar los servicios públicos, los cuales forman parte del salario indirecto, pero también postular la reconstrucción del salario real, la revalorización de la fuerza laboral en su conjunto.

El Estado burgués, como corresponde al de la cuarta transformación, tiene una capacidad limitada de intervención, dictada por su función constitutiva: promover la acumulación de capital. La institucionalización 
de conquistas obreras y democráticas resulta contradictoria y conflictiva, pese a que se diga que él mismo es producto de luchas sociales pretéritas, sobre todo en el plano electoral. Los derechos sociales constitucionales son positivos para los trabajadores porque dichas conquistas protegen sus condiciones de vida, así sea limitadamente. Para los capitalistas resultan negativos, pues los consideran como postulados extraños en su Estado; que sustraen recursos y evitan que esas mismas actividades sean campo fértil a la valorización de capital.

La defensa de la universidad pública como un bien público entraña la necesidad de fortalecerlas institucionalmente, incentivar su reforma desde adentro, no como imposiciones desde arriba, promover la investigación y generación de conocimiento vinculada a las necesidades del desarrollo nacional y regional, propiciar el trabajo colectivo y multidisciplinario e interinstitucional, reestablecer el vínculo entre las comunidades universitarias y sus entornos, su comunidad, con la variedad de sectores sociales, ámbitos culturales, ambientales y espaciales. Asimismo, significa defender a las universidades como un bien común, un espacio de la sociedad a su servicio.

\section{Mercantilización o gratuidad}

Mediante la demonización de lo público y la crisis inducida de la eduación superior, las políticas de austeridad, privatización y mercantilización, entre otras, se proponen como opciones de salvamento, inclusive como medidas redentoras en un clima de moralización. Con ese cometido se pergeñan discursos alevosos, se lanzan datos fuera de contexto, se vilipendia a las universidades y se ofrecen alternativas de educación privada. 
Ante el estrangulamiento financiero y la presión para obtener ingresos propios, las universidades públicas pervierten su misión al cobrar los servicios educativos, como si fueran mercancías. Al respecto se fijan cuotas y colegiaturas a los estudiantes, se cobran cursos, seminarios, congresos y diplomados, se venden servicios de investigación y consultoría. Actualmente, las universidades públicas, sobre todo las estatales, dependen del cobro a estudiantes de colegiaturas, cuotas y trámites (inscripción, titulación, revalidación). Esto mercantiliza un bien público al fijar precios y desnaturaliza la esencia misma de la educación pública.

La mercantilización de la educación funciona como mecanismo de financiamiento que pretende subsanar el déficit estatal, pero también como un dispositivo para que las universidades se reconviertan y adopten, en distinto grado, la forma de universidad-empresa, con vías a la privatización relativa.

Los sucesivos gobiernos neoliberales, del Partido Revolucionario Institucional (PRI) y del Partido Acción Nacional (PAN), y sus aliados en las cámaras legislativas, han venido pervirtiendo el principio cardinal de la gratuidad de la educación pública. En el Artículo $3^{\circ}$ constitucional se decía, hasta 1993, que «toda la educación que imparta el Estado será gratuita». En la administración de Carlos Salinas de Gortari, en 1993, se modificó el Artículo $3^{\circ}$ constitucional para decir que la educación superior pública sería simplemente «promovida» por el Estado, en descargo de la noción que decía que sería «impartida» por el Estado; esta modificación exime al Estado de la responsabilidad de garantizar la gratuidad, por lo que dicha exigencia se reduciría al tramo comprendido entre la educación preescolar y la educación media superior.

En la universidad pública se ha debatido y defendido la gratuidad de la educación ante las varias intentonas por cobrar e incrementar las cuotas 
escolares. El caso más emblemático ha sido el de la Universidad Nacional Autónoma de México (UNAM) en 1985-1986, ${ }^{9}$ y aún antes cuando en los cincuenta el entonces rector Salvador Subirán intentó subir las cuotas. En esa Universidad, que marca mucho del derrotero de la educación pública superior, la lucha y la defensa por la gratuidad de la educación ha perdurado en las últimas dos décadas, periodo en el cual ha estado vigente la contrarreforma neoliberal: en 1992 irrumpe un movimiento para evitar que la nueva interpretación les permitiera subir las cuotas, y en 1999-2000 hubo una huelga que duró 10 meses, debido al proyecto del rector Francisco Barnés para aumentar el cobro de colegiaturas. Gracias a las movilizaciones se han logrado mantener cuotas simbólicas, como ninguna otra institución en el país, por ejemplo, continúa el cobro de 20 centavos por inscripción aprobado en 1966 para estudiantes de bachillerato y licenciatura; sin embargo, esto no quita que se cobren en los hechos diversos servicios administrativos y educativos. Gracias a la movilización estudiantil, los siguientes rectores tuvieron que asumir el precepto de gratuidad de la educación y a pronunciarse por la obligatoriedad del Estado para financiar la educación pública, pero esa determinación política no se ha generalizado en las demás universidades públicas del país, donde se han venido menguando esos preceptos básicos.

Para establecer una conexión efectiva entre educación y desarrollo, máxime en un país colmado de desigualdades sociales como México, y con miras al establecimiento de un nuevo régimen de gobierno que pretende

${ }^{9}$ Cuando la constitución decía que «la educación que imparta el Estado será gratuita», los abogados de la rectoría de la UNAM decían que había que interpretarlo, que se refería a la educación básica y media superior, no a la superior. Y decían que las universidades autónomas no era educación que impartía el Estado, a pesar de que el financiamiento viene principalmente del Estado. 
impulsar un proyecto de transformación social, a todas luces resulta impostergable que la educación pública se convierta en un auténtico derecho social para toda la población y que el Estado adquiera la obligación de ofrecer espacios educativos a la población que lo demande. Por ello se requiere que el Estado garantice que la educación pública sea gratuita en todos los niveles, es decir, que se desmercantilice por completo y se ofrezca como un derecho social y un bien público.

Proponer que la educación superior pública debe ser gratuita, implica una obligación pública que no exonera a las universidades autónomas. La jurisprudencia de la Suprema Corte de Justicia de la Nación ha sido contrastante sobre la gratuidad en la educación superior, en particular sobre el cobro de cuotas: por una parte, ha obligado a la Universidad Michoacana de San Nicolás de Hidalgo (UMSNH) a que reconozca la gratuidad y en consecuencia impidió que la Universidad cobrara cuotas de inscripción a 469 alumnos amparados, en referencia a la Constitución de Michoacán, aunque fuera autónoma; pero en el caso de la Universidad Juárez Autónoma de Tabasco (UJAT) consideró lo contrario, es decir, la primera sala y la segunda sala de la SCJN establecen criterios en sentido contrario sobre la gratuidad de la educación pública superior, en particular sobre el cobro de cuotas (Soberanes, 2018).

A efecto de garantizar el derecho social que entraña la educación pública, y en previsión de eventuales controversias constitucionales, amparos y procesos jurídicos de interpretación, se precisa que el Artículo $3^{\circ}$ constitucional esté redactado de manera incontrovertible y que al efecto exprese claramente que la educación superior que imparta el Estado, incluyendo a las instituciones a las que la ley otorga autonomía, será gratuita y obligatoria. Además se requiere configurar un piso presupuestal 
suficiente para hacer realidad para desmercantilizar y afianzar la gratuidad de la educación. ${ }^{10}$

\section{Selectividad u obligatoriedad}

Bajo los criterios de calidad y excelencia se han introducido mecanismos de selectividad para el acceso a la educación superior que tienen un trasfondo clasista. En la pauta de selectividad median factores institucionales tanto dentro de las universidades (presupuestos, programas educativos, infraestructura) como de las autoridades educativas (financiamiento, proyectos educativos, política de calidad y excelencia), factores sociales (desigualdades sociales, discriminación) y familiares (ingresos, apoyo) y factores económicos (mercados laborales).

La universidad pública mexicana ha cambiando su cariz popular y democrático de los setenta, a un perfil más neoliberal, selectivo y tecnocrático, es decir, se elitizó. Al incentivar la competencia entre estudiantes para acceder a los estudios universitarios y al cobrar cuotas, se ha ido cerrando el paso a las clases populares y abriendo espacios a sectores medios y altos, que además disponen de la alternativa de la educación privada, con lo cual se están gestando élites educadas y masas populares deseducadas.

Los jóvenes pobres suelen ser relegados de los planteles universitarios por vías directas e indirectas. Entre las primeras, destaca el hecho de que no sean aceptados por los exámenes de admisión, que actúan como filtros y tienen como referencia determinados cupos máximos por carreras, pero ${ }^{10}$ Algunas estimaciones sugieren que, de entrada, para implementar el precepto de la gratuidad en México se requiere un monto aproximado de 13 o 14 mil millones de pesos al año. 
a su vez este criterio de selectividad responde a que pueden disponer de una preparación educativa más limitada que no les permite concursar en igualdad de condiciones por un lugar, no disponen del suficiente bagaje cultural ni de las relaciones suficientes para insertarse en el mundo universitario; pero también existen causales indirectos, que los disuade de siquiera concursar, como el no disponer de recursos suficientes para afrontar los gastos de manutención y el pago de cuotas, colegiaturas, libros, materiales y transporte, o porque tienen la necesidad de trabajar o porque no perciben ninguna expectativa favorable al cursar una carrera frente a un mercado laboral igualmente excluyente.

Entre las principales manifestaciones de desigualdad social en México se encuentra la exclusión del sector educativo. La insuficiencia en la cobertura en la educación superior expresa una profunda deuda social del Estado, en tanto se desvanece un derecho crucial, y un signo de exclusión social que afecta, principalmente, a las clases populares. Si bien en las casi dos décadas de este siglo, México pasó de dos millones de estudiantes en 2001 a 4.5 millones en 2018, por lo que la cobertura creció de 32 por ciento a 38.4 por ciento y podría alcanzar 39.4 por ciento en 2019, el esfuerzo es notoriamente insuficiente. Actualmente, en México existen poco más de 4.2 millones de estudiantes en educación superior, lo que representa apenas una tasa de cobertura de 38.4 por ciento del grupo de edad entre $18 \mathrm{y}$ 22 años, el cual estaría abocado a incursionar en ese nivel de estudios. Esto pone al país 10 puntos porcentuales por debajo del promedio de América Latina y el Caribe, que es de 48 por ciento.

Es sintomático del sistema universitario excluyente que la tasa de rechazo de la mayoría de las universidades autónomas es superior a 50 por ciento. En ese rubro destacan la UNAM, el IPN y la UAM; sin embargo, en 


\section{LA DISPUTA POR LA UNIVERSIDAD PÚBLICA}

los tecnológicos y normales las tasas son inferiores, inclusive algunas instituciones tienen espacios subutilizados. Además, debe considerarse la elevada tasa de deserción de quienes logran incursionar en la carrera universitaria, que en algunos casos puede superar 40 por ciento y, por si fuera poco, el hecho de que sólo 38 por ciento logra graduarse, según la OCDE.

Si en la administración de Enrique Peña Nieto (2012-2018) se había comprometido a alcanzar una cobertura de 40 por ciento en educación superior, la propuesta de obligatoriedad requiere un esfuerzo incremental en la tasa de cobertura, que supere el umbral de 40 por ciento no alcanzado en el sexenio anterior y que cuando menos aspire a alcanzar los niveles más altos logrados por países de América Latina y el Caribe. Sin embargo, el proyecto de la cuarta transformación es muy modesto, y plantea que al final del sexenio, en 2014, se alcance la meta de una tasa bruta de cobertura de 50 por ciento (incluye a grupos más allá de la edad normativa del grupo de edad de 18 a 22 años que están matriculados en educación superior en modalidad escolarizada y no escolarizada) y en 2030 de 60. Una meta insuficiente, si se toma como máximo posible la cobertura total, que no se ha alcanzado en ninguna parte del mundo, pero todavía inferior a las tasas actuales registradas en países como Argentina (85.7 por ciento) y Chile (90.3), y todavía abajo de Costa Rica (54 por ciento), Uruguay (55.6) o Colombia (58.7). ${ }^{11}$

${ }^{11}$ Como sucede con la proyección de otros indicadores en tiempos de la cuarta transformación, signados por la austeridad y el decrecimiento, los diversos organismos tienen que bajar las expectativas de crecimiento. Lo mismo sucede para el rubro eductativo. Referente a esto, «la meta de la ANUIES para 2024 es también una reducción respecto de lo que la asociación planteaba en 2012, cuando consideraba posible llegar en 2022 a 60 por ciento de cobertura, según el documento Inclusión con responsabilidad, que fue presentado al presidente Enrique Peña Nieto en su momento. La meta del sexenio era llegar a 40 por ciento» (Sanchez, 19 de agosto de 2018). 
Actualmente, la capacidad instalada de las IES en su conjunto es cercana a un millón de lugares para el primer ingreso, lo cual incluye a programas escolarizados, mixtos y no escolarizados, en tanto que el egreso de bachillerato es de 1.3 millones al año. Por lo que la capacidad de absorción es de 80 por ciento de egresados de media superior. Pero no existe un trasvase automático, pues median factores restrictivos como los exámenes de admisión, los cupos por carrera, el interés de los estudiantes, los problemas económicos, la falta de expectativa laboral, etcétera.

El antídoto de la selectividad y elitismo de la política universitaria es la obligatoriedad. Pero el principio de que la educación pública sea obligatoria recae invariablemente en el Estado. De modo que conferirle un carácter obligatorio a la universidad pública no significa una imposición a los jóvenes dentro del rango de 18 a 22 años, la edad normativa para cursar la universidad, para que ingresen de manera forzada a un programa educativo, ni tampoco entraña un requerimiento a sus padres o tutores, menos aún concita una sanción legal o un descrédito público. En estricto sentido, la obligatoriedad se refiere a que el Estado, como macroinstitución responsable de impartir la educación pública, adquiere por entero dicha obligación, y en tal medida asume el deber de garantizar los espacios suficientes a los jóvenes que solicitan ingresar a la educación pública superior, pero no sólo se aboca a los jóvenes sino que también se adhiere al precepto de una educación irrestricta, independientemente de la edad, puesto que se hace extensiva a mayores de edad que lo soliciten y que indudablemente hayan cubierto los requisitos académicos previos. Al asumir el compromiso de la obligatoriedad, el Estado estaría saldando, en definitiva, una profunda deuda social en materia educativa y realizaría una política de justicia social de trascendencia histórica. 


\section{LA DISPUTA POR LA UNIVERSIDAD PÚBLICA}

Sin embargo, si persiste el mismo esquema presupuestal educativo centrado en la austeridad y no se formula un educativo sexenal, bien articulado, con planes, programas, acciones y objetivos muy claros y compartidos por las comunidades universitarias y las autoridades educativas, de antemano resulta previsible que la meta de 50 por ciento de cobertura para 2024 es prácticamente inalcanzable. Al menos en el renglón presupuestal, la meta de alcanzar la cobertura de 50 por ciento en términos brutos implica un incremento de poco más de 1.2 millones de estudiantes en la educación superior, 170 mil estudiantes nuevos cada año durante el sexenio. Eso implica movilizar recursos estatales y adaptar a las instituciones.

La meta mínima de 50 por ciento de cobertura o una más ambiciosa que iguale a los países de América Latina y el Caribe con mayor cobertura (Cuba con 95 por ciento), requiere un compromiso decidido del Estado, que no puede cumplirse, de ninguna manera, bajo el paraguas restrictivo de la austeridad (llámese «republicana», «franciscana» ofrancamente neoliberal), sino que se precisa de una rectoría del Estado en la educación y de un soporte presupuestal que lo haga realidad. En tal caso, es apremiante implementar una reforma fiscal progresiva, y no sólo para soportar un proyecto educativo progresista. Para sustentar los derechos sociales y los bienes públicos, como salud, educación, alimentación, vivienda, transporte y trabajo, plataforma mínima para pensar en una transformación social en pauta cuando menos posneoliberal se requiere, indudablemente, una reforma fiscal progresiva. Sólo así se puede hacer realidad y garantizar perdurabilidad a propuestas tesoneras como la gratuidad y la obligatoriedad en la educación pública en todos los niveles, incluyendo el superior. En eso se cifra buena parte de un proyecto de regeneración social de largo aliento. 
Si para 2024 se espera que la matrícula alcance 5 millones de estudiantes, el aporte del UBBJ funcionando a su máxima capacidad incluiría sólo 50 mil o 60 mil estudiantes, por lo que apenas contribuiría con 1 o 1.5 por ciento de la matrícula esperada. Ello no resolverá el gran problema de la exclusión educativa. El cuello de botella se encuentra en las universidades públicas.

Frente a la tentativa de incrementar la matrícula con el concurso de las universidades privadas y de la creación de un sistema de 100 universidades, debe replantearse la estrategia y centrarse en el principal soporte de la educación pública superior, que son las universidades públicas autónomas, tanto las federales y las estatales, para que sean el soporte fundamental del crecimiento de la matrícula, porque ya están constituidas, tienen una masa crítica, realizan investigación científica, promoción de la cultura, actividades de vinculación y extensión, cuentan con tradición y posibilidades de innovación, además de que pueden establecer campus regionales y ampliar la oferta de carrera vinculadas a las necesidades del desarrollo nacional y satisfacer las demandas de los estudiantes. Además, debe incluirse a las otras modalidades, de educación superior, como las normales, las universidades tecnológicas y las universidades interculturales.

Con todo, el tema de la obligatoriedad de la educación pública superior no sólo es un tema de presupuestos públicos y de cumplimiento de indicadores internacionales, como la cobertura, sino que es un tema de justicia social que pasa por garantizar el derecho a la educación o garantizar la universalidad en la educación donde se posibilite la participación de todas las clases y sectores de la sociedad, comenzando por los sectores excluidos, subalternos, por lo que es crucial hacer una interpretación desde una perspectiva de clase y también un análisis del papel que la educación cumple en la formación de generaciones de científicos, tecnólogos, 
artistas, intelectuales, investigadores. Es necesario actuar de manera consciente en un escenario social contradictorio y conflictivo, más allá de la observancia de indicadores de desempeño y criterios técnicos en el diseño presupuestal.

Indiscutiblemente, se requerirán fondos especiales para garantizar la gratuidad y obligatoriedad de la educación superior, con énfasis en la universidad pública autónoma, no sólo es asunto de reformas legales. ${ }^{12}$

\section{Diferenciación o equidad institucional}

El sistema universitario mexicano, donde coexisten instituciones públicas y privadas, muestra un patrón de desarrollo desigual, que tiene como trasfondo el papel asignado en la reproducción social y el sistema de poder, el cual ha variado con el cambio de la universidad popular o nacionalista a la universidad neoliberal o mercantilizada de los últimos tiempos.

Las universidades de élite ahora son las privadas y cumplen el papel de formar a las clases altas para el manejo de empresas y la tecnocracia que ocupa cargos estratégicos en el Estado; las universidades públicas metropolitanas consideradas «nacionales», que antes cumplían un papel de élite, han sido degradadas, aunque siguen formando profesionistas, científicos, intelectuales y creadores, quienes cada vez más encuentran condiciones adversas para su inserción en los mercados laborales. Las universidades

${ }^{12}$ Una estimación provisional considera lo siguiente: el costo y presupuesto de educación superior obligatoria ascendería a 9 mil 400 millones de pesos, el aumento de alumnos para una cobertura de 56 por ciento en un horizonte de seis años requeriría de 65 mil millones adicionales, es decir, 10 mil 500 millones cada año. 
públicas de los estados padecen condiciones presupuestales muy adversas y se constriñen a incidir en su ámbito local, y las universidades privadas proliferan como negocios con el sólo cometido de mercantilizar la formación universitaria con programas educativos muy limitados pero con el propósito de hacer negocios.

En el sector de las universidades públicas autónomas hay una gran diferenciación presupuestal. Las grandes universidades disponen de presupuestos suficientes, amplios y diversificados, que no sólo les permite cubrir con sustentabilidad las actividades universitarias sustantivas sino que además realizan actividades accesorias, promoción política de autoridades y pueden ampliar sus campus en diversas regiones del país, donde ya existen universidades públicas estatales; en cambio, las universidades autónomas estatales, sobre todo las pequeñas, disponen de presupuestos austeros, restrictivos e insuficientes, que las colocan en el límite de la subsistencia, sin recursos para cumplir a cabalidad la misión educativa universitaria, por ejemplo la investigación, la vinculación social y la difusión de la cultura, y a menudo tienen problemas para cubrir lo más elemental: el pago de las nóminas; obviamente no disponen de recursos para desplegar programas de expansión y desarrollo institucional y más bien acumulan deudas y conflictos internos, por lo que están muy sujetas a los condicionamientos externos, es decir, a la heteronomía.

Hay que advertir que el tránsito o retorno hacia lo público, luego de una larga noche de insomnio neoliberal, entraña una problemática completamente dispar entre las universidades públicas, que han experimentado grados desiguales de desarrollo, de tal suerte que para la mayoría de las universidades públicas autónomas estatales que disponen de estructuras financieras endebles, donde el ingreso extraordinario captado por el 
cobro de cuotas puede representar 20 por ciento o más del presupuesto general, el desafío de compensar los recursos que dejarían de captar al eliminar la fuente de ingresos de espuria, al menos desde la óptica del bien público, es por demás mayúsculo y tendría que ser garantizado decididamente por las instancias estatales. Otra sucede con las grandes universidades, donde el cobro de cuotas representan una participación mínima en el presupuesto global, como en la UNAM, donde se captan 35 millones de pesos de cuotas anuales, si es que todos los estudiantes pagan 100 pesos, aunque muchos están exentos por diversos motivos (hijos de sindicalizados, etcétera), sobre un presupuesto anual de 44 mil millones de pesos. Desde esa lógica, se tiene que revertir la intencionalidad gubernamental de rebajar el presupuesto, como pretendía al eliminar 35 por ciento de los recursos, para alcanzar el ideal de la gratuidad y obligatoriedad, es decir, hacer realidad la educación pública como en derecho social generalizado.

En contraste, hay universidades estatales que destinan la mayor parte de su presupuesto en el pago de la nómina, además de cubrir adeudos y pensiones, por lo que el recurso destinado a actividades sustantivas, como investigación, docencia, vinculación y difusión de la cultura se reduce al mínimo, cuando no se extingue. ${ }^{13}$

En el límite de la subsistencia han sido colocadas varias universidades autónomas de estados subsumidos en las condiciones más degradantes de subdesarrollo. Luego de una serie de recortes sistemáticos al presupuesto de las universidades públicas, que se ha agudizado desde 2016, al menos

${ }^{13}$ Pero incluso las megauniversidades, como la UNAM, experimentan grandes desigualdades en su seno. Al respecto, los profesores de esa institución han denunciado que sólo 4.38 por ciento del presupuesto asignado a la universidad se gasta en los salarios de los docentes. Los profesores ganan 90 pesos por hora frente a grupo y sólo 5 por ciento tiene un acceso hasta de 30 horas por mes (Guzmán, 21 de agosto de 2018). 
nueve universidades públicas estatales enfrentan déficit presupuestal permanente: Universidad Autónoma de Sinaloa (UAS), Universidad Autónoma de Nayarit (UAN), Universidad Autónoma de Zacatecas (UAZ), Universidad Autónoma Benito Juárez de Oaxaca (UABJO), Universidad Autónoma del Estado de Morelos (UAEM), Universidad Juárez Autónoma de Tabasco (UJAT), Universidad Autónoma del Estado de México (UAEM), Universidad Autónoma de Chiapas (Unach) y Universidad Michoacana de San Nicolás de Hidalgo (UMSNH). Estas instituciones han sido sometidas a programas de austeridad y aún así arrastran un pasivo acumulado de 16 mil 677 millones de pesos, según ANUIES.

En un proyecto de transformación social, se debe contemplar una política federalista y de descentralización. Para el caso de las universidades públicas, debe considerarse un trato equitativo y proporcional a las necesidades y potencialidades de las universidades, para el presente y futuro. Reproducir el esquema según el cual las universidades metropolitanas hablan siempre a nombre de toda la nación y las estatales a nombre de su localidad, es anacrónico y elitista, el conocimiento tiene que democratizarse y diversificarse, también su entramado institucional.

\section{Flexibilización y precarización o revalorización del trabajo académico}

El término de flexibilización también ha sido adoptado de los esquemas productivos, donde se implementa la gestión de la acumulación flexible en la industria y entre otras cosas se espera un trabajador polivalente. Por homologación, en el caso del trabajo académico, se trata de un trabajador que 
realice diversas tareas, no sólo la encomendada en términos tradicionales o contractuales, sino que idealmente debe ser un docente, investigador, gestor, difusor y un administrador de sí mismo y un copartícipe de grupos académicos que emulan los círculos de calidad, en este caso educativa. Asimismo, la política de precarización laboral introducida en los mercados laborales, para generalizar la inseguridad laboral y la desvalorización del trabajo, se ha introducido en el ámbito universitario. Proliferan los puestos precarios de trabajadores académicos contratados a tiempo determinado, profesores de asignatura u hora clase, que pueden o no ser recontratados o ser despedidos.

La austeridad y la precarización propician que no se generen nuevas plazas académicas seguras y completas, preferentemente de perfiles de alto nivel con doctorado y aptos para la docencia y la investigación, sino que las plazas se fragmentan en puestos precarios al grado en que se han convertido en la mayoría de la base de trabajadores universitarios. Las formas de contratación precaria vulneran el contrato colectivo, pues muchas veces se realizan al margen de su normatividad, a la vez que precarizan en los hechos el empleo y propician que los noveles trabajadores asuman una actitud sumisa y clientelar ante la parte patronal. La política de contratación de académicos que se ha impuesto es por honorarios, sin examen de oposición, sin requerimiento de título y con consecuencias para el trabajador pues entra desprovisto de prestaciones sindicales.

Las condiciones extremas de precarización incluyen contrataciones por honorarios, que se pagan en una sola emisión y que no implican seguridad social. Con los esquemas de inseguridad en el empleo, se están gestando nuevos perfiles de trabajadores universitarios, sin experiencia política ni sindical, propensos a aceptar condiciones de trabajo degradadas, supeditados a esquemas de control de grupos de poder. 
Amén de que opera una política general de congelamiento de salarios contractuales e implementación de complementos salariales por concurso y asociados a la productividad sin vinculación a antigüedad o prestaciones: los estímulos a la docencia y las becas de investigación (SNI). La política de diferenciación entre trabajadores académicos, pérdida de trabajo colectivo y de solidaridad, para impulsar la competencia, las distinciones y el elitismo.

La gestión de la austeridad asociada a la precarización laboral permite un encuentro entre las autoridades universitarias de Hacienda y la SEP con cada una de las rectorías universitarias para imponer programas de ajuste de la planta laboral, en consonancia con ajustes en otros rubros de la vida universitaria. Ello redunda en que, por ejemplo, el número de afiliados universitarios a la seguridad social disminuya, entonces se tiene una amplia masa precarizada y además sin posibilidades de exigir derechos, por lo que queda como reserva bajo el control de las autoridades, que puede fungir como votantes cautivos, en el caso de que se permita participar en elecciones dentro de las universidades.

Ello redunda en una fractura intergeneracional. Por una parte, no hay estímulos suficientes para una jubilación decorosa, por lo que profesores de edad avanzada aplazan hasta el límite de sus capacidades el retiro, y ello demerita su rendimiento intelectual y académico, por razones obvias, además de que obstruye el ingreso de nuevos profesores, y, por otra parte, los académicos que se están retirando son suplidos por maestros de asignatura, académicos precarizados de origen, quienes sustentarán los cursos de nivel medio superior y los programas de licenciatura. El hecho de ejercer cargas laborales que quedaron disponibles por jubilaciones, decesos o de docentes que fungen temporalmente como funcionarios, son asignadas a docentes con tiempos determinados y suplencias. Todo ello 
redunda en desatención a los alumnos y en deficiencias en el proceso de enseñanza-aprendizaje.

Esto genera conflictos internos, pues los académicos compiten por los puestos de trabajo, por una parte entre quienes demandan el respeto a la normatividad, la suspensión al personal académico contratado de manera irregular y el respeto al procedimiento contractual, y, por otra parte, quienes solicitan ingresar a la universidad a sabiendas de que las condiciones de contratación se conducen por la vía de la flexibilización y precarización extremas. De ahí que se disputen plazas de tiempo completo, pero también plazas de tiempo determinado, como las vacantes por suplencia y las cargas de trabajo temporal.

El antídoto es la configuración de una ciudadanía universitaria integral, que significa el goce de derechos plenos y el cumplimiento de deberes dentro del ámbito de una autonomía responsable y de un compromiso social irrenunciable. Los derechos no se asumen como privilegios, un rango elitista separado del resto de la sociedad, sino como una conquista social y una valorización del trabajo académico acorde con su aportación social, en tanto que los deberes se adscriben al cabal cumplimiento de la misión universitaria en el ámbito de la docencia, la investigación y la difusión de la cultura. En esa inteligencia, la universidad no se concibe como una ciudad aparte, un campus amurallado, sino que la universidad pública adquiere la forma de un bien común social, un especio abierto a la sociedad, sobre todo de las clases sociales populares, que pueden beneficiarse y apropiarse del conocimiento y los bienes generados por los universitarios, en tal sentido se concibe a la enseñanza como un derecho humano, al conocimiento como un bien libre y al quehacer universitario como parte de una cultura abierta, de libre acceso. 


\section{Calidad o criticidad}

En los ámbitos del poder, desde las autoridades educativas hasta los legisladores, pasando por los organismos empresariales y medios de comunicación, se ha discutido si la educación pública debe basarse en el postulado de la calidad o en el de la excelencia, términos que a la sazón pueden usarse de manera complementaria o intercambiable. La terminología parecería inocua e inobjetable, pero tiene un sustrato ideológico y efectos políticos. El término calidad proviene del sector industrial, específicamente en el sector automotor, donde se refería a la gestión de la calidad total (total quality management) en 1985, a partir de las técnicas de gestión empresarial que se implementaron desde las décadas de los cincuenta y sesenta del siglo pasado en la industria japonesa y que se expandieron mediante la conquista del sector automotor en Estados Unidos, que tenía como divisa el concepto de excelencia. Posteriormente, el término se transfiere de la manufactura a otros sectores, como los servicios, el gobierno y la educación.

El término de calidad es adoptado en el léxico internacional de la corriente principal (mainstream) sobre el desarrollo educativo. Al respecto, la Organización de las Naciones Unidas (ONU), en la Agenda 2030 denominada Transformar Nuestro Mundo: la Agenda 2030 para el Desarrollo Sostenible, incluye la educación de calidad con la idea de que: «Cuando las personas acceden a una educación de calidad, pueden escapar del ciclo de la pobreza. La educación contribuye a reducir las desigualdades y a lograr la igualdad de género», y la Organización de las Naciones Unidas para la Educación, la Ciencia y la Cultura (Unesco, por sus siglas en inglés) ha elaborado su discurso en torno a la mejora de la calidad educativa con su 
Agenda Mundial Educación 2030, y en la misma sintonía se pronuncian la Organización para la Cooperación y el Desarrollo Económicos (OCDE) y el Banco Mundial (BM).

A partir de esa cadena de transmisión, y bajo el influjo de la directriz empresarial que pervive en la cuarta transfromación, la Secretaría de Educación Pública (SEP) ha propuesto la sustitución del término de calidad por el de excelencia, en alusión a un proceso de mejora continua, rememorando la pauta de producción industrial. En el sector empresarial, los términos de calidad y excelencia han adquirido una evidente connotación productivista, con objeto de intensificar el proceso productivo y controlar la producción de mercancías de conformidad a los estándares del mercado; sin embargo, el trasplante de estos términos al sector educativo significa la adopción de vocablos marcados por la imprecisión y la inasibilidad.

Quienes promueven la aplicación de términos como calidad y excelencia en la educación se remiten al cumplimiento de los «estándares de calidad internacional» que se basan en los preceptos del mercado, y además suelen argüir que aquello que no tiene un costo, un precio, no es valorado por quien lo consume, en este caso el estudiante, por lo que se pretende justificar la fijación de cuotas y un sistema de cobros por los servicios administrativos y educativos que se ofrecen en las universidades, para que entonces los estudiantes sepan apreciarlo, y entre más caras sean, se supone que se asociará a un mayor grado de calidad y excelencia, y una mayor valoración social de las instituciones oferentes.

Paradójicamente, el significado mismo del pensamiento crítico es disputado y apropiado, desde las esferas más altas del poder económico. Nada menos que el Foro Económico Mundial (2018) reclama una formación de 
estudiantes en el pensamiento crítico, pero no como una forma de cuestionar el pensamiento dominante y el capitalismo contemporáneo, por lo contrario, se postula como una simple herramienta analítica para identificar y resolver problemas en el ámbito de los negocios, las empresas y el gobierno.

El Foro Económico Mundial (2018) propone una versión empresarial del pensamiento crítico y analítico, estrategias de aprendizaje, creatividad y originalidad e inteligencia emocional, en tanto habilidades que demandan las empresas. En tal sentido, establece que

las habilidades demandadas por las empresas en la nueva realidad son el pensamiento analítico e innovación; la resolución de problemas complejos; el pensamiento crítico y análisis; el aprendizaje activo y estrategias de aprendizaje; la creatividad, originalidad e iniciativa; la atención al detalle y confiabilidad; la inteligencia emocional; el razonamiento, resolución de problemas e ideación; el liderazgo e influencia social, y la coordinación y gestión del tiempo (FEM, 2018:12).

Las universidades organizadas en red promueven formas de movilidad internacional, como viene sucediendo con el Proceso de Bolonia en Europa y el Proceso Tuning en América Latina, al amparo de los esquemas de integración regional de libre comercio y la adopción de la educación superior como un espacio para la formación por competencias y visiones globales en los métodos de enseñanza.

Pero, claro está, que no todo lo que se presenta como crítico es, en el fondo, pensamiento crítico. Para ser reconocido como tal, al menos se precisa que se cuestione la organización económico-política-cultural vigente 
en la sociedad y las formas de pensamiento dominante que la justifican desde los ámbitos del poder, la academia y la ideología.

La universidad pública en América Latina y México ha sido sede y espacio para el despliegue de un cierto pensamiento crítico, donde ha florecido una teoría propia de la región, como el estructuralismo y la teoría de la dependencia, y donde se ha desplegado un marxismo y otras expresiones del pensamiento crítico. Se han gestado instituciones como la Comisión Económica para América Latina y el Caribe (Cepal), el Consejo Latinoamericano de Ciencias Sociales (Clacso) y la Facultad Latinoamericana de Ciencias Sociales (Flacso), entre muchas más, y las universidades públicas autónomas han albergado programas educativos, proyectos de investigación y publicaciones de gran importancia. En su momento, por ejemplo, la UNAM ha sido prácticamente la capital latinoamericana del pensamiento crítico, cuando albergó a intelectuales exiliados latinoamericanos y españoles. Esa vocación se ha ido perdiendo, aunque persisten algunos reductos de aquella tradición olvidada por el grueso de la comunidad universitaria.

Sin embargo, con el neoliberalismo se ha desmantelado el pensamiento crítico genuino y ha sido suplantado por un pensamiento convencional, apuntalado por el neoliberalismo, que se pretende único, pero que ha caído en el descrédito. Además se han impuesto formas de colonización académica que introducen los preceptos normativos de la ciencia y la académica generada en los países centrales, que corresponden al interés económico-político-cultural de sus capitales y poderes estatales expansivos. Evidentemente, no es posible un proyecto transformador fundado en la primacía de las llamadas fuerzas del mercado y, mucho menos, en el pensamiento metafísico, religioso y moralista. La expectativa de transformación 
social requiere, por necesidad, el cultivo del pensamiento crítico, el avance de la ciencia, la tecnología y la formación de nuevas generaciones de trabajadores del conocimiento y la cultura.

\section{Empresarialidad o compromiso social}

Que la universidad pública no es una empresa parece estar suficientemente claro (Laval, 2004), pero en la práctica se impulsa un modelo de universidad-empresa que concita la adopción de principios gerenciales en su organización y conducción, se adoptan criterios de mercado para cobrar a los estudiantes y vender servicios, se diseñan programas y pedagogías orientadas al mercado y se producen recursos humanos (capital humano) para el mercado laboral estratificado. Desde la perspectiva del Banco Mundial:

Tres tipos de habilidades son cada vez más importantes en los mercados laborales: las habilidades cognitivas avanzadas, como la capacidad para resolver problemas complejos; las habilidades socioconductuales, como el trabajo en equipo; y las combinaciones de habilidades que son factores predictores de adaptabilidad, como el razonamiento y la autoeficacia. Para desarrollar estas habilidades se requieren sólidas bases de capital humano y un aprendizaje permanente (BM, 2019:3).

Desde la absorción de lo público por lo privado, mediante modelos de gestión como la nueva gerencia pública, donde lo público se gestiona con arreglo a principios gerenciales del mundo empresarial, para el nuevo 
management del marketing educativo, el éxito institucional radica en la gestión de directivos para implementar la tecnología mediante una gestión eficiente según los preceptos del mercado. En tal sentido, se justifica que las instituciones educativas que adopten esos modelos gerenciales serán capaces de sobrevivir en un mundo plagado de competencia, eficientismo y productividad. La exhortativa es dar un golpe de timón en la política educativa y orientarse al mercado, para vender, es decir, deliberadamente comercializar lo que se concibe en tal caso como producto educativo. El sistema educativo ideal para estos menesteres es el que se sumerge en un idílico mercado libre donde conviven o compiten instituciones públicas y privadas que para sobrevivir tienen que diferenciarse, competir y vincularse en el mercado, como si fuesen empresas.

La pulsión de competencia irrumpe como acto legítimo de validación institucional, que borra la solidaridad y el compromiso social, si se quiere acceder a las subvenciones, mantener la matrícula, preservar proyectos de investigación y respaldar la docencia, entre otras actividades. Las evaluaciones son modalidades de atemperar o conducir la competencia, pero competir no es garantía de obtener las subvenciones. En tiempos neoliberales donde prima la austeridad, disciplina fiscal y superávit primario, los recortes afectan a la educación pública, y más a la que se considera irrelevante para el mercado. El eficientismo programático y la austeridad presupuestal imponen la necesidad de optimizar los gastos e inversiones que permitan la consecución de una supuesta «rentabilidad» de cada institución. Los términos de rentabilidad y viabilidad, tan caros a la órbita empresarial privada, se introducen y ganan terreno en la educación pública.

La empresarialidad educativa impone la norma de la optimización de recursos, la eficiencia, la calidad, la excelencia, la evaluación, la medición 
y la obtención de resultados. Se privilegia la competencia, rentabilidad, participación de mercado y captación de alumnos. Por lo que más que planes de estudios, pedagogías, didáctica, ciencia, epistemología, se prefiere hablar de estrategias, de gestiones, de planes de negocio, de planificación en el medio y largo plazos, sin dejar de pensar en captar recursos propios, apoyos de empresas, fundaciones y organismos internacionales. Además, la captación y retención de alumnos, tratados como consumidores de servicios educativos, se percibe como medio para captar recursos líquidos («recursos propios») que permitan pagar las nóminas y gastos diversos, además de conservar determinadas actividades docentes e investigativas. En esa carrera, se estimula la diferenciación entre instituciones y utilizar herramientas de comunicación y el marketing para difundir dicha diferencia.

El discurso empresarial ha permeado el diseño de las políticas educativas mediante la introducción de conceptos como «calidad», «excelencia» y «competitividad», que han sido promovidos por la OCDE y el BM para ensamblar el modelo educativo con el modelo económico-político neoliberal. Bajo ese influjo, el proyecto de educación pública asume un carácter resueltamente neoliberal, además de conservador y neocolonialista.

Desde la visión convencional se ha insistido en el término de «capital humano» dotado de pensamiento crítico, ${ }^{14}$ es decir, la formación de capacidades técnicas y científicas aplicadas a las exigencias concretas del

\footnotetext{
${ }^{14}$ Según el Foro Económico Mundial, para ser más competitivos, se requiere, como prioridad 1: «Capital Humano: Es el recurso más básico e importante para generar crecimiento económico, por lo que es clave generar habilidades para tener un pensamiento crítico y capacidad de análisis. Se tienen que transformar las habilidades de la fuerza de trabajo y no sólo esperar que se haga a través del sistema tradicional de educación, las empresas también deben participar en esta nueva realidad» (FEM, 2018).
} 
mercado laboral, o dicho de otro modo, la formación de fuerza de trabajo calificado por los estratos de la división social del trabajo. En esta visión se modelan estudiantes y egresados con habilidades prácticas para el trabajo, pero no capacidades cognitivas para pensar, reflexionar, criticar, crear y proponer. Por lo mismo, algunas materias esenciales para la formación intelectual crítica han sido consideradas como irrelevantes: historia, filosofía, ética, es decir, los estudios humanísticos y las ciencias sociales, o en casos más dramáticos, ahí donde germinaba el pensamiento crítico más profundo, en las escuelas de economía, las ciencias económicas se han convertido en un sucedáneo de las matemáticas o una escuela de negocios, que persiguen «mundos ideales» adscritos al libre mercado, el estatismo o el dogmatismo (Acosta, 2018).

Desde los niveles básicos de educación hasta los superiores, se introduce la llamada cultura emprendedora y con la llamada «nueva escuela mexicana» se propone instaurar la educación financiera, como parte de la nueva política social de los organismo financieros internacionales basada en el enfoque de «bancarizar» a los sectores populares, tal como ocurre con los programas sociales de la cuarta transformación que utiliza a la banca privada como mediación entre el Poder Ejecutivo y los individuos beneficiarios.

El restablecimiento del compromiso social de la educación pública reclama un cambio de orientación, donde se fomente la educación democrática, crítica y popular al calor de las nuevas condiciones científicas, tecnológicas y pedagógicas. En efecto, se precisa un nuevo modelo educativo basado en una escuela democrática orientado a educar una ciudadanía pensante, crítica, interdependiente y solidaria. Desde la educación pública se pueden procrear generaciones de ciudadanos cultos, informados, críticos y democráticos, con 
formación humanística, científica, tecnológica, interesados en participar, ser justos, actuar éticamente y ser incluyentes.

Siempre existe el riesgo de sobredimensionar el alcance de la educación y descargar en esa función social la responsabilidad de generar cambios de mayor calado que escapan al ámbito de sus funciones, por lo que se aviene la duda de si se cambia la educación para cambiar la economía o si en la práctica sucede al revés. Más allá de esa disyuntiva, cabe advertir que los cambios sociales de gran calado reclaman también cambios culturales sustantivos, donde la educación, la ciencia, la tecnología y las diversas ramas del trabajo creativo y cognitivo intervienen. Pero en todo caso se trata de proyectos conscientemente asumidos, no dejados al garete de las fuerzas del mercado o de intereses creados que modulan subrepticiamente las políticas de transformación. Ante esa tentativa plantean problemas como si el proyecto educativo al que se aspira se reduce a educar para el trabajo o si en una visión de largo aliento se educa para formar una ciudadanía crítica, informada y creativa. Y, en esa misma tesitura, si se investiga para fines utilitarios, como pueden ser los del crecimiento económico y la rentabilidad empresarial que le es consustancial, o si se investiga para entender los grandes problemas históricos y estructurales que están en la base del subdesarrollo y la dependencia, pero también para cultivar el intelecto y desarrollar la cultura en un sentido amplio, lo cual también incluye la necesidad de satisfacer la curiosidad, de concitar la duda, estimular el cuestionamiento, imaginar mundos posibles. 


\section{Empleabilidad o formación de ciudadanía crítica}

Según el criterio neoliberal, la pertinencia de las universidades y de las carreras se mide, como los demás ámbitos de negocio, por la rentabilidad. Para ello se tasa a la educación como si fuese una mera inversión empresarial, donde el producto final, representado por el título universitario se valora en el mercado como una mercancía, siempre que se obtenga un puesto laboral, mediante la remuneración a la que accede el novel universitario y luego se contrasta con lo que se ha invertido en la carrera educativa, ya sea que se haya sustentado en créditos, recursos familiares, becas o subsidios públicos. Existen rankings en Estados Unidos que miden directamente lo que gana un egresado universitario frente a lo que le costó la carrera; en México se evalúa la «rentabilidad» de algunas carreras, y según ese criterio, por ejemplo, estudiar Minas es más rentable que estudiar Ciencia Política, porque los ingenieros metalúrgicos ganan el doble que los politólogos (IMCO, $\mathrm{s} / \mathrm{f}$ ), ello en un contexto donde, grosso modo, el extractivismo minero ha cobrado gran auge y donde los procesos democráticos están en descrédito. De forma que se valora a las universidades según lo que se ha invertido en ellas, de acuerdo al esquema convencional de costo-beneficio.

En un sentido más estructural se puede apreciar que existe una desvinculación relativa entre las universidades y el mercado laboral, a partir de la evidencia acusada de desocupación de los egresados, ello significa la desvalorización en términos simbólicos y económicos de carreras y profesiones, títulos y cédulas, en suma, del trabajo de los universitarios y del proceso educativo subyacente. Para los analistas convencionales, esto significa una «ineficiencia en el financiamiento destinado a la educación superior o las tasas de retorno». 
Inexorablemente, el avance científico-tecnológico destruye puestos de trabajo y modifica otros, pero también genera empleos diseminados en sectores y tareas nuevas. Estos cambios alteran las exigencias de especialización, pues mientras algunas profesiones resultan anacrónicas, otras devienen sobrecalificadas, en tanto que se abren posibilidades para nuevas carreras y especialidades vinculadas a la innovación. Por ejemplo, la última ola de la revolución cuaternaria abre espacios para expertos en profesiones digitales como el internet de las cosas, la realidad virtual, la big data y científicos de datos, que disponen de oportunidades laborales en telecomunicaciones, entretenimiento, servicio, banca y seguros.

La transformación de la estructura productiva hacia la manufactura, los servicios y la urbanización, que torna a la economía mexicana como una de las más diversificadas de Latinoamérica, pero también con mayor grado de dependencia respecto de Estados Unidos, impacta directamente en los mercados laborales y genera una desvinculación con el sistema de educación superior. De hecho, hay una desvalorización acusada de los títulos universitarios, que no garantizan más la inserción laboral ni la movilidad social, como se deduce de los indicadores de empleabilidad de los egresados universitarios, los «retornos financieros de la educación» y las «capacidades base».

La política de precarización laboral desmoraliza el costo social y el esfuerzo escolar de la formación universitaria, tanto desde el punto de vista salarial, como desde la perspectiva de la formación de capacidades productivas en la economía nacional.

A la pregunta de educar para qué, con qué orientación, existen varias respuestas acordes a diversos intereses. La visión tecnocrática plantea centrarse en la formación técnico-científica que permite generar innovación, 
según esta perspectiva un país avanza en la medida que tiene más conocimientos que le permitan afrontar la complejidad del mundo actual: pensamiento matemático y conocimiento de ciencia y tecnología, pero los conocimientos técnicos por sí solos no solucionan problemas ni generan una visión de país ni fomentan el ánimo de las personas. Una perspectiva complementaria descansa en la capacitación para el trabajo, según los requerimientos específicos del sector empresarial y las ramas más dinámicas eslabonadas en cadenas de valorización global, donde conciben la educación como el desarrollo de habilidades (o habilidades blandas) el desarrollo de capacidades como el trabajo en equipo, emprendimiento, trabajo bajo presión, habilidades de trato social, herramientas y soluciones para insertarse en el mercado laboral. Otra visión es la humanística, que concibe a la educación en la visión y los valores que involucra en la persona en su totalidad, transformación interna de la persona, educación de orden ético. Una idea relevante: la ciudadanía, todos somos responsables del bien público, de que el país avance. La educación universitaria abocada al mercado laboral con programas de la SEP y la STPS, y la generación del conocimiento. Finalmente, existe una visión educativa desde la pedagogía crítica, con visión descolonizadora, en aras de una educación emancipadora, aquí se concibe a la universidad crítica y emancipadora y a la pedagogía crítica: capacidad de pensar, centrada en el estudiante, ubicado en un contexto, en busca de una praxis social.

La educación pública es atacada con denuedo por los sectores conservadores y la tecnocracia neoliberal, que aún permea en los llamados frentes progresistas, como la cuarta transformación. Al efecto, se desprestigia a las universidades públicas, a los sindicatos, a los profesores, a los científicos, a los estudiantes. Se difunden diagnósticos descontextualizados, estadísticas 
manipuladas y se emprende una andanada mediática incontestada. El cometido es generar un ambiente de incertidumbre y de descrédito sobre la educación superior, además de formar nuevas generaciones de estudiantes como si fuesen consumidores acríticos en lugar de educar a personas que cuestionen y que sean creativas.

\section{Pedagogía digital o pedagogía crítica}

Los avances en las tecnologías de la comunicación y la información que se han propagado en todas las esferas de la vida tienen un influjo importante en el proceso de enseñanza, que pueden ser aprovechadas para fortalecer las herramientas pedagógicas, pero también pueden entronizarse como el centro de atención, en detrimento de la relación entre profesores y estudiantes y de la formación de pensamiento crítico.

Está cobrando notoriedad la propuesta de disolver la educación presencial, donde prima el vínculo inmediato entre profesores y alumnos en el aula, con el soporte de un pizarrón o proyector. En lugar de ello, se enarbola el uso de nuevas tecnologías, como la realidad virtual, la inteligencia artificial o el big data, es decir, un paquete de herramientas que pueden ser usadas en el aula, o a distancia, que amerita cambios de los enfoques pedagógicos y las formas de adquisición de conocimiento mediante formas de aprendizaje basadas en la analítica de datos (learning analytics).

En el marco de la llamada cuarta revolución industrial y de la industria 4.0, se proclama ahora la educación 4.0, donde se asume que el estudiante, educado en competencias empresariales y usando diversos dispositivos tecnológicos estaría en el centro del proceso de enseñanza en la educación 
superior, el cual pasaría de ser instruccional a interactivo. La realidad virtual o aumentada recrearía situaciones reales de trabajo en el aula o la resolución de problemas cotidianos. También supone la posibilidad de desarrollar investigaciones entre universidades, incluso con industrias, sobre problemas prácticos.

Este enfoque centrado en el uso de las tecnologías de comunicación e información se vincula a las nociones de flexibilidad curricular y movilidad estudiantil, que posibilitarían la obtención de créditos en distintas instituciones, tomar cursos en línea y tomar materias en diferentes campus o universidades. En tal sentido, los currículos se presentan como programas flexibles, emprendedores y centrados en un nuevo perfil de estudiante, donde se supone que el egresado debe adoptar una vocación emprendedora. El estudiante se torna empresario de sí mismo, predispuesto a venderse en un mercado laboral sumamente competido, por lo que debe adquirir las habilidades que exigen el gran capital, en consonancia con un mercado laboral flexible y precario.

La adopción acrítica de estos preceptos supone subirse al tren del progreso tecnológico sin un mínimo escrutinio ético, político y social, sino dejándose llevar por la inercia, la tendencia, el pragmatismo y el inmediatismo. Las revoluciones tecnológicas e industriales no son neutrales, son acuñadas y controladas por grandes corporativos que resguardan los avances tecnológicos bajo la cobertura del sistema de patentes y la propiedad intelectual, subsumen el trabajo de los científicos y tecnólogos y, en definitiva, controlan nichos de mercado donde se alojan ganancias extraordinarias. Sus beneficios son monopolizados. En la misma medida, debe advertirse los efectos en el proceso de enseñanza y tomarse en cuenta los efectos de la inteligencia artificial en el trabajo y la educación y la tentativa 
de constreñir el proceso educativo a las directrices empresariales. Claro está que, en lugar de reducir la educación a la ideología empresarial, y con ello empobrecerla, tiene que enriquecerse, diversificarse, adaptarse a los cambios e innovar para promover procesos de mayor calado en pos de la transformación social sustantiva.

Aquí el desafío radica, como siempre, en los usos preferenciales de la investigación científica, la tecnología y la enseñanza, si se canalizarán exclusivamente a los intereses de corporaciones privadas (la ganancia empresarial), que se benefician directa e indirectamente de los recursos públicos, o si se canalizarán a resolver los problemas estructurales del subdesarrollo. ${ }^{15}$ ¿Hacia donde se canalizará el trabajo potenciado, es decir, el conocimiento, la tecnología y la inventiva de los universitarios?

En otro sentido, que puede ser complementario, el concepto de desarrollo humano, desde la visión del liberalismo social se emplea para conferir oportunidades y libertad a los individuos a través de la educación, la salud y la alimentación como medio de inserción a los ámbitos del mercado. Sin cuestionar las dinámicas estructurales del capitalismo, se pretende que los individuos adquieran capacidades para incursionar en la sociedad mercantil, sea como asalariados o consumidores solventes.

${ }^{15}$ Por lo pronto, el gobierno federal asignó para el Conacyt un presupuesto austero de 24 mil 764 millones de pesos, que representa una disminución de 10.4 por ciento respecto de 2018, algunos programas desaparecieron y otros fueron reducidos a su mínima expresión dentro de la dependencia. 


\section{Evaluación punitiva o evaluación institucional}

La implantación del término de calidad o su sustituto, la excelencia, generó efectos prácticos en la gestión educativa, sobre todo mediante la implementación de mecanismos de evaluación asociados al acceso a recursos en el contexto de la austeridad, entonces la terminología tomó significados particulares en torno a la «rendición de cuentas académicas», la evaluación y la designación de determinados programas como de excelencia, en desdoro de aquellos que no lograban pasar el umbral de los comités de evaluación.

Desde los ochenta, en el contexto del congelamiento de los salarios contractuales, los mecanismos de evaluación en las universidades fueron reorientados para establecer figuras complementarias al salario y otorgar los programas de estímulos a la productividad docente y el Sistema Nacional de Investigadores (SNI), pero en apariencia las repercusiones han sido positivas, aunque para sectores restringidos, pero se ha desencadenado la diferenciación salarial y la segmentación de los docentes e investigadores y se han establecido incentivos perversos para un productivismo medido en puntajes y la entronización del individualismo, además de que el mecanismo de evaluación se ha desgastado. Luego de más de tres décadas de evaluaciones continuas (Aboites, 2012) no se tienen diagnósticos finos y concretos sobre las universidades y el papel de la educación superior en el desarrollo nacional. Las evaluaciones estandarizadas vinculadas al reparto de recursos condicionados no generan procesos de aprendizaje en el sector educativo y en los actos pedagógicos, sino que inoculan los mecanismos de control, burocratismo y heteronomía.

En lugar de implementar evaluaciones individualizadas, que tienden a diferenciar a los profesores e investigadores, a establecer estratos y a implantar 
una lógica de competencia, la ruptura del trabajo colectivo y la pérdida de solidaridad, porque termina por trabajarse para cumplir puntos que abonen a una mejor posición en las evaluaciones, es mejor hacer evaluaciones del funcionamiento del sistema educativo en su conjunto y de cada nivel educativo, además de evaluación de las instituciones, desde la SEP, el Conacyt hasta las universidades, pero no evaluaciones individuales. Las evaluaciones además han tornado la función educativa como una carrera burocrática, esto es lacerante porque en muchos casos los profesores dejan de asumirse como intelectuales, como trabajadores del conocimiento, la ciencia y la cultura, y se consideran cada vez más como técnicos de la educación que tienen que cumplir estándares de calidad. Además, la remuneración de docentes e investigadores no debería de estar condicionada por evaluaciones individuales, deben mejorarse las condiciones salariales y laborales en general.

\section{Bloque de poder estructurado o democratización}

La idea de que en las universidades no se necesita la democracia está muy extendida. Se supone que la mayoría de la población está formada por los estudiantes, quienes son aves de paso, y sería peligroso que instrumentos como el voto universal permitieran que este sector tomara las decisiones, por lo que los ejercicios electivos, si acaso existen, son ponderados, para diluir el peso poblacional y establecer votos ponderados entre los sectores, lo cual se refleja en la conformación de los principales órganos de decisión, como los consejos universitarios, donde se asignan pesos por sector, pero usualmente tiene el control la administración central. Siendo instituciones del saber, se supone que deberían de ser gobernadas por los que 
saben, los académicos, pero usualmente quienes gobiernan son los burócratas políticos que se han formado en las instituciones y se han especializado en su conducción, para formar una pequeña clase política interna, que conoce bien los mecanismos de la operación política interna y externa y es capaz de perpetuarse, reproducirse y ampliar sus ámbitos de poder, hasta formar un bloque de poder estructurado, que eventualmente puede ser disputado por grupos de poder emergentes que intentan removerlo y ocupar su lugar. Estos bloques de poder son comandados por los líderes políticos y la burocracia, y están soportados por alianzas políticas con los sectores académicos, administrativos, estudiantiles y trabajadores manuales; además de que se apoyan en alianzas políticas con sectores externos, como determinados partidos políticos, gobernantes, medios de comunicación y otros sectores, como el empresariado o las Iglesias.

Sin embargo, bajo la política de neoliberalización de las universidades, estos bloques si bien se han consolidado hacia adentro, han perdido capacidad de gestión hacia afuera, por lo que han reconvertido su papel y se han especializado en «bajar recursos» de las diversas instancias gubernamentales y de administrar la crisis, lo cual quiere decir que internalizan las nuevas disposiciones heterónomas del Estado y aplican con determinación los programas de austeridad, ajuste y reestructuración institucional, según lo dictan las normas exógenas.

El problema es que la gobernabilidad universitaria se reduce a la predominancia de grupos políticos que internalizan las pautas estatales de austeridad, evaluación condicionada, mercantilización, precarización laboral y exclusión de estudiantes. Es decir, a bloques burocráticos de poder que gestionan la crisis y son consecuentes con las políticas de estandarización de la calidad educativa según la norma internacional. 
Frente a la figura del bloque de poder estructurado que gestiona la crisis como correa de transmisión de la contrarreforma universitaria corresponde generar contrapoderes o formas de poder democrático que reconfiguren a las comunidades universitarias, el resarcimiento de su gobernabilidad, apego a la legalidad y democratización dentro del ámbito de una autonomía ejercida con responsabilidad social. Esto significa detonar procesos deliberativos colectivos, lugares donde se puedan discutir los problemas y encontrar colectivamente las soluciones.

La universidad representa un espacio privilegiado para discutir, debatir, analizar los problemas y la posibilidad de arribar colectivamente a propuestas sin recurrir a la violencia. La restitución de las comunidades universitarias, con el concurso de sus partes: estudiantes, profesores, trabajadores y autoridades, significa superar la pauta de individualismo, competencia, diferenciación, elitismo, y privilegiar procesos participativos, políticas equitativas, el trabajo colectivo. En suma, constituir un movimiento universitario que incluya a los sectores, pero que también unifique a diversas comunidades universitarias en temas comunes y compartidos; no se trata de que las universidades actúen como meros agentes individuales, aislados, sino que se articule una fuerza universitaria mayor, en el horizonte nacional y, eventualmente, internacional.

No cabe duda de que la mejor forma de gobierno es la que los propios universitarios se puedan otorgar a sí mismos, dentro de un ámbito de autonomía, legalidad y responsabilidad social. Por analogía con la política, ¿cuál será la mejor modalidad: el gobierno aristocrático, donde gobiernan los que detentan el poder y los privilegios; el gobierno plutocrático, donde gobiernan los que amasan el dinero; el gobierno republicano, donde gobierna el pueblo mediante sus representantes; el teocrático, donde gobiernan los 
que manejan la representación divina; el de los sabios, donde gobiernan los que saben; el burocrático, donde gobierna la casta de la burocracia política. Corresponde, en cada caso, a las comunidades universitarias deliberar sobre las mejores formas de gobierno, aun a sabiendas de que las comunidades pueden ser ilusorias, pues a menudo son heterogéneas, con diversidad de intereses y puntos de vista.

Entonces se requiere habilitar espacios dentro de la universidad para discutir las opciones y construcción de consensos mínimos que reconstruyan la comunidad. Reconocer factores que han fracturado a la comunidad: sistema escolarizado que fomenta el individualismo y la competencia en lugar del trabajo en equipo y la cooperación. La solución estará en la participación. Crear una atmósfera para la interlocución de todos los sectores. Se requiere crear un sujeto colectivo organizado desde las comunidades universitarias. ¿Cuál es el sector más movilizado; cuál tiene mayor fuerza política? Profesores y estudiantes. Unir lo que está separado: profesores de asignatura y de tiempo completo. Se precisa un movimiento que se proponga triunfar.

\section{Gestión de la crisis o transformación universitaria}

La reforma universitaria ipso facto ha sido la neoliberal, en el curso de las últimas dos décadas, cuando menos. Para ello se ha inducido la crisis, mediante el ajuste presupuestal y las políticas concomitantes de desvalorización del trabajo académico, la subsunción del trabajo cognitivo, la exclusión educativa, la mercantilización y privatización, la evaluación condicionada, entre otros dispositivos. Para acceder al presupuesto público 
ordinario y extraordinario, y para simular rescates recurrentes de las universidades, se han impuesto programas de austeridad (shock), a la manera de cartas de intención que imponen los organismos financieros internacionales a los Estados deudores acompañados de severos programas de ajuste estructural neoliberal. En tal caso, los grupos de poder interno, las administraciones y las instancias colegiadas operan como gestores de la crisis, que se ven forzados a implementar las políticas que vulneran la autonomía y la misión educativa en general.

La superación de la crisis universitaria significa el abandono de la política de austeridad y de sujeción de las universidades, para incentivar su regeneración y transformación como instituciones inapreciables para la generación de conocimiento, información, ideas y propuestas para la transformación social. Son los espacios de investigación, enseñanzas y deliberación donde concurre una masa crítica de intelectuales, científicos, tecnólogos, analistas, artistas y creadores que pueden suministrar ideas y propuestas centrales para acometer los grandes problemas nacionales para superar el subdesarrollo y la dependencia.

El Estado mexicano tiene un nivel insuficiente de gasto en educación pública, que se ejerce de manera desigual y condicionada, sin advertir la necesidad de fortalecer el sistema de educación pública en su conjunto y la formación de nuevas generaciones con mayores capacidades científicas, tecnológicas, intelectuales y culturales. No sólo para abatir las enormes desigualdades sociales, que se acusan en la cuestión educativa, sino también para generar las bases científicas y políticas de un proyecto de transformación social, que no se detenga en la premisa neoliberal de servir a la productividad de las empresas conectadas en redes de acumulación global, donde se perpetúa la transferencia sistemática de valor y se reprenda 
el incremento del grado de explotación laboral, al tiempo en que se preservan las ganancias empresariales, en un círculo vicioso de subdesarrollo y dependencia.

Un hecho estructural constante ha sido que México, como América Latina, carece de la formación de un trabajo potenciado, es decir, de un trabajo colectivo con cimiento científico-tecnológico, pero también de consistencia intelectual y cultural, que le brinde un soporte para la industrialización, la acumulación autónoma y el desarrollo nacional.

No obstante que se ha incrementado la formación educativa y la investigación y desarrollo, más que la óptica individualista y competitiva de «desarrollo de talentos de alto nivel», el factor crítico es la creación de capacidades colectivas en los ámbitos de la ciencia, la tecnología, la cultura y el pensamiento, donde el sistema de educación pública superior sea reformulado y las universidades públicas y los centros de investigación sean reformadas para impulsar programas de investigación y desarrollo, además de programas de educación acordes a las necesidades de transformación social.

\section{Defensa o transformación}

Las tendencias conservadoras dentro de las universidades están latentes y se manifiestan de diversas formas: internalización de determinaciones exógenas de grupos de poder (gobiernos de turno, partidos políticos, Iglesias, empresas, medios de comunicación, fundaciones, organismos internacionales) reproducción de ideología dominante, reproducción de jerarquías y diferenciación sociales, reproduce la doxa académica (pensamiento convencional), desvinculación con el entorno y la sociedad, formación de 
bloques de poder estructurado, preservación de ámbitos de poder de los bloques dominantes, espacio de proyección para personajes de la clase política, preservación de estructuras académicas y organizacionales obsoletas, pedagogía tradicionalista, formas autoritarias de enseñar, reproducción de carreras tradicionales obsoletas, la gestión de la crisis como forma de conducción institucional sin elaborar diagnósticos y programas de reforma, la propagación de conflictos y disputas internas por asumir los puestos de conducción institucional, pero sin proyecto de transformación, siguiendo la inercia.

Sin embargo, frente al persistente embate estatal y de otros agentes de los poderes fácticos, se impone la necesidad de adoptar tácticas defensivas desde adentro de la universidad pública, que interpelan el sentido histórico de la institución y su potencial transformador. De ahí que la defensa se necesaria, pero no sólo como una fuente de trabajo, desde el punto de vista sindicalista; no sólo como una escalera de movilidad social, desde un punto de vista estudiantil; no sólo como un espacio de prestigio y difusión, desde un punto de vista científico; no sólo como un espacio de desarrollo personal y de grupo, para los gestores y autoridad. La defensa de la educación pública se inscribe en procesos de más largo aliento, que de antemano venza el autoritarismo de los cuerpos de gobierno de un Estado y la tendencia hacia el envejecimiento o anquilosamiento de las universidades, y que se inscriba en un proceso de verdadera transición social, que abra una perspectiva de salida a la grave situación actual, un proceso de ruptura con el capitalismo subdesarrollado, que sólo puede ofrecer degradación humana, colapso ambiental, regresión social y ataque a las conquistas sociales.

Para impulsar conocimiento, profesionalización, investigación y proyectos de transformación social, es imprescindible mejorar sustancialmente la educación superior pública, y de arriba hacia abajo, y de abajo 
hacia arriba, todos los niveles de educación, con el concurso de profesores, investigadores, estudiantes, funcionarios públicos y sectores de la sociedad interesados. Asumir la gama de problemáticas de la universidad para darle vida a la universidad.

En lo tocante a la educación superior pública, y en particular a la universidad pública autónoma, sigue siendo apremiante impulsar una reforma universitaria que recupere los principios básicos que dan sustento a la misión educativa universitaria: autonomía, gratuidad, obligatoriedad, sustentabilidad financiera, bien público y desarrollo científico y cultural. La universidad es un espacio comunitario que permite un cierto desarrollo humano, pero no se generaliza al resto de la sociedad, por lo que debe ampliarse su espectro de formación y difusión de la ciencia y la cultura, e instaurarse como un espacio abierto, como un genuino bien común, comenzando por la reivindicación de la educación pública superior como un derecho humano.

\section{Referencias}

Aboites, Hugo (2012), La medida de una nación. Los primeros años de la evaluación en México. Historia de poder y resistencia (1982-2012), México, UAM, Clacso, Ítaca.

Acosta, Alberto y John Cajas (2018), «De las «ciencias económicas` a la posteconomía.

Reflexiones sobre el sin-rumbo de la economía», Ecuador Debate (103).

Aguirre, Alberto y Daniela Pastrana (9 de mayo de 1999), «Huelga en la UNAM. Más allá de las cuotas», La Jornada, en: https://www.jornada.com .mx/1999/05/09/mas-cuotas.html 
Banco Mundial (BM) (2019), Informe sobre el desarrollo mundial 2019. La naturaleza cambiante del trabajo, Washington, Banco Mundial.

Didriksson, Axel y Alma Herrera (coords.) (2002), La transformación de la universidad mexicana. Diez estudios de caso en transición, México, Miguel Ángel Porrúa.

Foro Económico Mundial (FEM) (2018), The Future of Jobs Report 2018, Ginebra, FEM, en http://www3.weforum.org/docs/WEF_Future_of_Jobs_2018.pdf (2018), The Global Competitiveness Report 2018, Ginebra, FEM, en http:// www3.weforum.org/docs/GCR2018/05FullReport/TheGlobalCompetitivenes sReport2018.pdf

García Cantú, Gastón (1993), Javier Barros Sierra 1968, México, Siglo XXI.

Guzmán, Andrea (21 de agosto de 2018), «La UNAM paga bajos salarios a sus maestros», CCNews, en https://news.culturacolectiva.com/mexico/maestros-de -la-unam-piden-aumento-a-salarios/

Instituto Mexicano para la Competitividad (IMCO) (s/f), «Compara carreras», en http://imco.org.mx/comparacarreras/\#!/

Laval, Christian (2004), La escuela no es una empresa. El ataque neoliberal a la enseñanza pública, Barcelona, Paidós.

Mariátegui, José Carlos (2007), Siete ensayos de interpretación de la realidad peruana, México, Era.

Márquez Covarrubias, Humberto (2016), «Nubarrones en el jardín del conocimiento: la universidad pública bajo el asedio estatal», Estudios Críticos del Desarrollo, 6(10).

Marx, Karl (2007), A propósito de la cuestión judía, Buenos Aires, Del Signo.

Mella, Julio Antonio (2 de noviembre de 2002), «El concepto socialista de la reforma universitaria» (septiembre de 1928), Rebelión, en https://www.rebelion. org/hemeroteca/argentina/mella021102.htm 


\section{LA DISPUTA POR LA UNIVERSIDAD PÚBLICA}

Muñoz, Alma y Alonso Urrutia (29 de mayo de 2019), «Intelectuales y científicos, entre los inconformes por austeridad: AMLO», La Jornada, en https://www. jornada.com.mx/ultimas/politica/2019/05/29/intelectuales-y-cientificosentre-los-inconformes-por-austeridad-amlo-7960.html

Orden Jurídico Nacional (s/f), «Artículo tercero de la constitución», en http:// www.ordenjuridico.gob.mx/Constitucion/articulos/3.pdf

Organización para la Cooperación y el Desarrollo Económicos (OCDE) (2019), Higher Education in Mexico: Labour Market Relevance and Outcomes, París, OECD Publishing.

Ponce, Aníbal (1986), Educación y lucha de clases, México, Editores Mexicanos Unidos.

Rodríguez, Arturo (17 de diciembre de 2018), «Hay que hacer más con menos: AMLO ante críticas por recortes», Proceso, en https://www.proceso.com.mx/564 149/hay-que-hacer-mas-con-menos-amlo-ante-criticas-por-recortess

Román, José Antonio (17 de diciembre de 2018), «ANUIES se inconforma por recorte a fondos de universidades», La Jornada, en https://www.jornada.com. mx/ultimas/2018/12/17/anuies-se-inconforma-recorte-a-universidadescae-6-2-6697.html

Sader, Emir, Hugo Aboites y Pablo Gentili (eds.) (2008), La reforma universitaria. Desafíos y perspectivas noventa años después, Buenos Aires, Clacso.

Sánchez, Arturo (19 de agosto de 2018), «Reconoce ANUIES rezago en cobertura educativa a nivel superior», La Jornada, en https://www.jornada.com. $\mathrm{mx} / 2018 / 08 / 19 /$ sociedad/029n2soc

Soberanes, José María (2018), «La gratuidad de la educación pública en la jurisprudencia de la Suprema Corte de Justicia de la Nación», Cuestiones constitucionales (39). 